\title{
Enhancement of the Anti-inflammatory Efficacy of Betamethasone Valerate via Niosomal Encapsulation
}

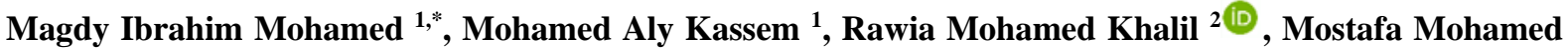 \\ Younis $^{2(\mathbb{D})}$, Asmaa Badawy Darwish ${ }^{2}{ }^{\mathbb{D}}$, Abeer Salama ${ }^{3(\mathbb{D})}$, Marwa Anwar Wagdi ${ }^{2}$ \\ 1 Department of Pharmaceutics and Industrial Pharmacy, Faculty of Pharmacy, Cairo University, Kasr El-Aini street, Cairo, \\ 11562, Egypt; magdymohamed1 @ hotmail.com (M.I.M.), mohamed.kassem@Pharma.Cu.Edu.eg (M.A.K.); \\ 2 Pharmaceutical Technology Department, Pharmaceutical Industries Research Division, National Research Centre \\ (Affiliation ID: 60014618), 33 El-Buhouth street, Dokki, Giza, 12622, Egypt; rawia_khalil@yahoo.com (R.M.K.), \\ most_younis@hotmail.com (M.M.Y.),dr-asmaaa@hotmail.com (A.B.D.), marwaanwar2@gmail.com (M.A.W.); \\ 3 Pharmacology Department, Medical Research Division, National Research Centre (Affiliation ID: 60014618), 33 El- \\ Buhouth street, Dokki, Giza, 12622, Egypt; berrotec@yahoo.com (A.S.); \\ * Correspondence: magdymohamed1@ @otmail.com;
}

Scopus Author ID 55413617900

Received: 27.01.2021; Revised: 5.03.2021; Accepted: 10.03.2021; Published: 25.03.2021

\begin{abstract}
Betamethasone valerate-loaded niosomes were formulated to improve drug antiinflammatory efficacy and reduce its systemic side effects by providing prolonged and localized drug delivery into the skin. Niosomes were prepared by thin-film hydration using different molar ratios of surfactant, cholesterol, and charge inducers. Formulations were characterized for entrapment efficiency, morphology, size, and zeta potential. In-vitro release and stability studies were conducted on selected formulations. Two niosomal gels were evaluated for spreadability, $\mathrm{pH}$, rheological behavior, ex-vivo skin permeation, and in-vivo anti-inflammatory efficacy. Formulations showed high encapsulation efficiency reaching $92.03 \pm 1.88 \%$. Vesicles were spherical in shape, ranging from 123.1 to $782 \mathrm{~nm}$, and had large negative values of zeta-potential. They showed a biphasic release pattern which was more sustained than free drug suspension. Niosomes demonstrated good physicochemical stability under refrigeration for up to 3 months. Niosomal gels exhibited good spreadability, suitable pH values, favorable rheological behavior, and higher skin permeation than the plain gel. In-vivo studies revealed that niosomal gels showed a better sustained anti-inflammatory effect than drug plain gel and the marketed product, which was confirmed by further histopathological examination of paw tissues. Niosomal gels are promising formulations for sustained local delivery of betamethasone valerate.
\end{abstract}

Keywords: betamethasone valerate; niosomes; anti-inflammatory; in-vitro release kinetics; rheological behaviour; permeation.

(C) 2021 by the authors. This article is an open-access article distributed under the terms and conditions of the Creative Commons Attribution (CC BY) license (https://creativecommons.org/licenses/by/4.0/).

\section{Introduction}

Corticosteroids are one of the oldest and potent treatments for different inflammatory conditions [1]. However, their use is limited by adverse effects often occurring at the systemic level [2]. Lately, there has been a major interest in developing new drug delivery systems for corticosteroids, enhancing drug skin retention and minimizing the amount penetrating systemic circulation upon topical application [3].

Niosomes are non-ionic surfactant vesicles having a bilayer structure formed by selfassembly of hydrated surfactant monomers [4]. The bilayer is a unilamellar or multilamellar enclosing aqueous solutes solution, while the lipophilic components are in the bilayer itself [5, 
6]. They are preferred in topical delivery over other vesicular systems as they are nonimmunogenic, biocompatible, biodegradable [7], and exhibit high chemical stability [8].

Niosomes have been reported to enhance dermal localization of many topical drugs by improving their residence time in the stratum corneum and epidermis [9], strengthen their efficacy by minimizing side effects associated with systemic drug absorption [10].

Betamethasone-17 valerate, being a corticosteroid, has been widely utilized to treat several inflammatory and allergic, dermatological conditions, including atopic dermatitis and psoriasis [11]. It is very potent and has a half-life of 36 - 54 hours which allows a lower dose to be employed [12]. Betamethasone binds to a specific intracellular receptor resulting in the modulation of multiple gene transcription, which causes the suppression of the production of inflammatory mediators like leukotrienes and prostaglandins and the inhibition of inflammatory cells recruitment into the skin [13].

Many approaches have been reported to enhance the dermal delivery of betamethasone. They have been formulated in solid lipid nanoparticles [11], nanostructured lipid carriers [14, 15], microemulsions [16], liposomes [17], and archaeosomes [18].

This study's primary objective was to evaluate the efficacy of betamethasone-17 valerate loaded-niosomes aiming to provide sustained and controlled delivery of the drug with a subsequent decrease in the undesirable side effects by targeting the drug to the dermal region while minimizing its absorption into the systemic circulation.

\section{Materials and Methods}

\subsection{Materials}

Betamethasone valerate (BMV) was gift samples from EPICO Company, Cairo, Egypt. Sorbitan monostearate (Span 60), Sorbitan monopalmitate (Span 40), DihexadecylhydrogenPhosphate (DCP), Cellulose membrane (molecular weight cut-off 12,000-14,000 g/mole), Octadecylamine (Stearylamine) (SA), Carrageenan and Cholesterol (CHOL) from Lanolin, minimum 99\% (GC) were purchased from Sigma-Aldrich, St. Louis, MO, USA. Chloroform HPLC, Methanol HPLC was obtained from Fisher Scientific, UK. Carbapol 934 was gift sample from CID Company, Cairo, Egypt. All solvents and chemicals utilized in all experiments were of analytical grade.

\subsection{Methods.}

\subsubsection{Preparation of BMV-loaded niosomes.}

BMV-loaded niosomes were prepared using the thin-film hydration technique initially reported by Baillie et al. [19]. In a $100 \mathrm{ml}$ pear-shaped flask of the (Büchi-M/hb-140, Switzerland) rotary evaporator, $100 \mathrm{mg}$ of non-ionic surfactants (Span 60 or Span 40) and cholesterol (CHOL) with or without charge inducing agent (CIA) (stearylamine or dicetyl phosphate) and $10 \mathrm{mg}$ of BMV were dissolved in $10 \mathrm{ml} \mathrm{CHOL}$ and rotated for 10 minutes at an adjusted temperature $\left(56 \pm 2^{\circ} \mathrm{C}\right)$ and a fixed speed of $150 \mathrm{rpm}$. Chloroform was slowly evaporated under reduced pressure to produce a thin, dry film of solid components on the rotating flask's inner wall. The thin film was hydrated with $10 \mathrm{ml}$ bidistilled water under rotation for 30 minutes, leading to niosomal suspension. The composition of BMV-loaded niosomal formulations was listed in Table 1. 
Table 1. In-vitro characteristics of betamethasone valerate niosomal formulations $(n=3)$.

\begin{tabular}{|c|c|c|c|c|c|c|c|c|c|}
\hline \multirow[t]{2}{*}{ Formula } & \multicolumn{4}{|c|}{$\begin{array}{c}\text { Formulation composition } \\
\text { (Molar ratio) }\end{array}$} & \multicolumn{5}{|c|}{ In-vitro characteristics } \\
\hline & Span 60 & Span 40 & CHOL & DCP & $\mathbf{S A}$ & EE\% \pm S.D. & $\begin{array}{c}\text { Mean Vesicle } \\
\text { Diameter }(\mathrm{nm}) \pm \text { S.D. }\end{array}$ & $\begin{array}{c}\text { Average Zeta- } \\
\text { potential }(\mathrm{mV}) \pm \text { S.D. }\end{array}$ & $\begin{array}{c}\text { Polydispersity } \\
\text { index }\end{array}$ \\
\hline $\mathrm{F}_{1}$ & 1 & - & 1 & - & - & $81.43 \pm 2.63$ & $145.7 \pm 17.06$ & $-34 \pm 9.96$ & 1 \\
\hline $\mathrm{F}_{2}$ & 1 & - & 1 & 0.1 & - & $88.41 \pm 3.11$ & $469.6 \pm 69.13$ & $-43 \pm 10.4$ & 0.806 \\
\hline $\mathrm{F}_{3}$ & 1 & - & 1 & - & 0.1 & $21.17 \pm 1.41$ & $539.7 \pm 89$ & $-20.9 \pm 7.24$ & 0.652 \\
\hline $\mathrm{F}_{4}$ & 2 & - & 1 & - & - & $75.94 \pm 5.81$ & $123.1 \pm 12.77$ & $-37.3 \pm 2.42$ & 1 \\
\hline $\mathrm{F}_{5}$ & 2 & - & 1 & 0.2 & - & $86.52 \pm 1.44$ & $167 \pm 39.14$ & $-39.1 \pm 9.04$ & 0.482 \\
\hline $\mathrm{F}_{6}$ & 2 & - & 1 & - & 0.2 & $14.44 \pm 1.91$ & $439.7 \pm 54.59$ & $-22 \pm 6.93$ & 0.864 \\
\hline $\mathrm{F}_{7}$ & - & 1 & 1 & - & - & $85.59 \pm 3.88$ & $319.5 \pm 40.67$ & $-39.9 \pm 6.95$ & 1 \\
\hline $\mathrm{F}_{8}$ & - & 1 & 1 & 0.1 & - & $92.03 \pm 1.88$ & $606.6 \pm 94.94$ & $-52 \pm 8.69$ & 1 \\
\hline $\mathrm{F}_{9}$ & - & 1 & 1 & - & 0.1 & $38.12 \pm 2.99$ & $782 \pm 108.3$ & $-26.4 \pm 7.01$ & 0.999 \\
\hline $\mathrm{F}_{10}$ & - & 2 & 1 & - & - & $81.74 \pm 1.61$ & $222.2 \pm 23.69$ & $-40.2 \pm 5.94$ & 1 \\
\hline$F_{11}$ & - & 2 & 1 & 0.2 & - & $85.01 \pm 2.72$ & $423.6 \pm 53.8$ & $-54.6 \pm 9.96$ & 1 \\
\hline $\mathrm{F}_{12}$ & - & 2 & 1 & - & 0.2 & $34.57 \pm 3.41$ & $753.6 \pm 97.41$ & $-18.5 \pm 6.27$ & 0.182 \\
\hline
\end{tabular}

2.2.2. Characterization of BMV-loaded niosomes.

\subsubsection{Entrapment efficiency (EE \%).}

Unentrapped BMV was separated from that entrapped inside the niosomes by cooling centrifugation (Union 32R, Korea) adjusted to $7000 \mathrm{rpm}$ (at $5200 \mathrm{x} \mathrm{g}$ ), for 30 minutes at $-4{ }^{\circ} \mathrm{C}$. Niosomal pellets were washed once with bidistilled water and recentrifuged for another 30 minutes at the same conditions [20]. Niosomal pellets, weighed about $100 \mathrm{mg}$ lipids-surfactants mixture, were resuspended in $10 \mathrm{ml}$ bidistilled water, and the amount of BMV entrapped in niosomes was estimated via the lysis of $1 \mathrm{ml}$ of niosomal suspension with $100 \mathrm{ml}$ methanol followed by ultrasonication in the bath-type ultrasonicator (Heated digital ultrasonic cleaner (SH 150 - 4L), MTI Corporation, USA) for 30 minutes. The obtained clear solution was measured spectrophotometrically at $\lambda_{\max } 238 \mathrm{~nm}$ (Shimadzu UV Spectrophotometer (2401/PC), Japan) versus drug-free niosomes, prepared using the same method, as blank [21].

Entrapment efficiency (EE \%) was calculated using the equation [22]:

$$
\mathrm{EE} \%=\frac{\text { Amount of drug entrapped }}{\text { Total amount of drug added }} \mathrm{X} 100
$$

\subsubsection{Vesicle size, zeta-potential, and polydispersity index determination.}

Vesicle size, zeta-potential, and polydispersity index (PDI) of the formulations were measured using Zeta-sizer (Malvern Zeta-sizer Nano ZS, Malvern Instruments, UK) [23]. Niosomal suspensions were diluted with deionized water in a ratio of 1:100 v/v [5] for vesicle size determination and a ratio of 1:10 v/v for zeta-potential determination. A sample was placed in a quartz cuvette, and measurements were taken at room temperature. PDI was determined as a measure of homogeneity [24] and was expressed as following [25]:

$$
\text { PDI }=\frac{\text { Standard deviation }}{\text { Mean droplet size }}
$$

\subsubsection{Transmission electron microscopy (TEM).}

About $1 \mathrm{ml}$ of niosomal suspensions were diluted ten folds with bidistilled water then mixed well before the investigation [26]. A drop of each sample was mounted on a 300-mesh carbon-coated grid and left to dry to a thin film. Before the films were completely dry, they 
were negatively stained with $0.5 \%$ phosphotungstic acid [27]. Films were inspected using TEM (JEOL, JEM-1230, Tokyo, Japan) at room temperature, and micrographs were taken at suitable magnifications.

\subsubsection{In-vitro release profiles.}

In-vitro release of BMV from niosomes was investigated using the dialysis method discussed by Li et al. [28] with slight modifications. This study was conducted on $\mathrm{F}_{1}, \mathrm{~F}_{2}, \mathrm{~F}_{4}$, $F_{5}, F_{7}, F_{8}, F_{10}$, and $F_{11}$. BMV niosomal formulations, viz; $F_{3}, F_{6}, F_{9}$, and $F_{12}$ were omitted as they showed obvious aggregations due to their low stability, which was reported in some other previous studies [29].

A sample from each niosomal suspension equivalent to $2 \mathrm{mg}$ BMV was transferred within a dialysis bag (Spectra/Por ${ }^{\circledR}$ with a molecular weight cut off 12000 - $14000 \mathrm{Da}$ ), previously soaked in the receptor medium, for 24 hours. The dialysis bag was dipped in a tightly closed bottle containing $100 \mathrm{ml}$ phosphate-buffered saline (pH 5.5): methanol mixture (60:40), based on BMV solubility characteristic [30], to fulfill sink condition. The bottle was transferred to a thermostatic shaking water bath maintained at a temperature of $32 \pm 2^{\circ} \mathrm{C}$ and rotated at 150 rpm. At predefined time intervals; 1, 2, 3, 4, 6, 8, 24, 48, 72, and 96 hours, 5 ml sample was withdrawn and replaced with an equal volume of fresh medium to preserve sink condition. The drug content in each sample was determined spectrophotometrically at $\lambda_{\max } 240.8 \mathrm{~nm}$. A separate investigation was conducted with free BMV suspension using the same method. , The cumulative percentage of drug released was plotted against time.

To illustrate the mechanism of drug release, in-vitro results were fitted to different kinetic models [31, 32] and the Korsmeyer-Peppas model [33, 34].

\subsubsection{Physical stability study.}

Four niosomal formulations were selected for this study which was; $\mathrm{F}_{4}, \mathrm{~F}_{5}, \mathrm{~F}_{8}$, and $\mathrm{F}_{10}$, for their high entrapment efficiencies and suitable release rates. $10 \mathrm{ml}$ from each formulation were sealed in $20 \mathrm{ml}$ glass vials wrapped with an aluminum foil protected from light and kept at refrigeration temperature $\left(2-8{ }^{\circ} \mathrm{C}\right)$ for 3 months [35]. Physical appearance was evaluated, and all formulations were evaluated regarding the percentage of drug retained and vesicle size after 1, 2 and 3 months of storage and compared with freshly prepared niosomal formulations.

\subsubsection{Preparation of BMV niosomal gel.}

Two niosomal formulations were selected for further studies viz., F5 representing Span 60 formulations and $F_{8}$ representing Span 40 formulations; they were selected for their high entrapment efficiencies and suitable release rates.

Niosomal gels were prepared by dissolving $100 \mathrm{mg}$ of Carbopol $934 \mathrm{in} 10 \mathrm{ml}$ niosomal suspension. Drops of triethanolamine were added (about 1-2 drops), to adjust $\mathrm{pH}$ to neutral value, with continuous stirring until homogenous niosomal gel was obtained [36]. The plain gel containing an equivalent amount of free BMV was prepared using the same method. 
2.2.6. Evaluation of BMV niosomal gel.

\subsubsection{Spreadability.}

The spreadability of $\mathrm{F}_{5}$ and $\mathrm{F}_{8}$ niosomal gels was assessed and compared with two marketed gel products. The test was carried out by pressing $1 \mathrm{~g}$ of each gel between two horizontal glass plates $(10 \mathrm{~cm} \times 20 \mathrm{~cm})$, and a standard weight of $25 \mathrm{~g}$ was placed on the upper glass plate for 1 minute. The formed circle diameter was measured and used as a comparative value for spreadability [37].

\subsubsection{2. pH measurement.}

The niosomal gel formulations' $\mathrm{pH}$ was measured using a digital $\mathrm{pH}$ meter (Thermo Fisher Scientific Inc., Orion VERSA STAR ${ }^{\mathrm{TM}}$, VSTAR 92, USA). The apparatus was calibrated then measurements were recorded by dipping the glass rod into the niosomal gels at $25{ }^{\circ} \mathrm{C}[38]$.

\subsubsection{Rheological behavior.}

The rheological behavior of the niosomal gels was investigated using a parallel-plate rheometer (Anton Paar, Physica MCR 301, Germany). $0.5 \mathrm{~g}$ of each niosomal gel was placed on the plate and left until the plate temperature attained $25 \pm 1^{\circ} \mathrm{C}$ [39]. Flow curve and viscosity of each formulation were registered for a total time interval of 6 minutes; 3 minutes during the ascending period by increasing the shear rate gradually from 1 to $200 \mathrm{~s}^{-1}$, followed by 3 minutes during the descending period by reducing the shear rate from 200 to $1 \mathrm{~s}^{-1}$ [40]. The flow behavior was studied using the regression analysis of log shear rate versus log shear stress, and Farrow's constant (n), which denotes deviation from Newtonian flow behavior, was calculated applying this equation [38]:

$$
\log G=n \log F-\log \eta
$$

Where: $\mathrm{G}$ is a shear rate $\left(\mathrm{s}^{-1}\right), \mathrm{F}$ is shear stress $(\mathrm{Pa}), \eta$ is apparent viscosity (Pa.s), and $\mathrm{n}$ (Farrow's constant) is the slope of $\log \mathrm{G}$ versus $\log \mathrm{F}$ plot. If $\mathrm{n}$ is less than one, this denotes dilatant flow (shear rate thickening) behavior, whereas $n$ values greater than one reveal pseudoplastic or plastic flow (shear rate thinning) [39].

The degree of thixotropy was assessed by measuring the hysteresis area (H.A.), between the upward and downward curves, using the trapezoidal rule [39].

\subsubsection{Ex-vivo skin permeation}

\subsubsection{Skin preparation.}

Full-thickness abdominal skin of albino mice was used for permeation studies. , The hair on the abdominal side of mice was removed by an electrical clipper one day before the experiment [41]. Mice were sacrificed by cervical dislocation, and skin was excised. Subcutaneous fats were cautiously removed. Animal experiments were carried out following institutional and national guidelines for animal care. 


\subsubsection{Ex-vivo permeation test.}

An ex-vivo permeation experiment was conducted to compare F5 and F8 niosomal gels' drug penetration profiles compared to BMV plain gel.

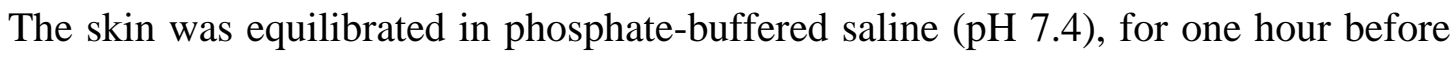
the experiment to simulate human blood $\mathrm{pH}$. The study was performed using vertical Franz diffusion cells (Hanson 6 unit assembly, Hanson Research Corp ${ }^{\circledR}$ ) with an effective diffusion area of $1.5 \mathrm{~cm}^{2}$ and $7 \mathrm{ml}$ of receiver chamber capacity [42]. Phosphate buffered saline (pH 7.4) containing $40 \%$ methanol was used as receptor fluid to fulfill sink condition [43], maintained at a temperature of $37 \pm 0.5^{\circ} \mathrm{C}$ [44], and stirred at $350 \mathrm{rpm}$ [45]. The skin was placed between donor and receptor compartments where the stratum corneum side facing the donor compartment [46]. The receptor medium was replaced every 30 minutes till it showed negligible absorbance, indicating complete skin stabilization. Accurately weighed $0.1 \mathrm{gm}$ of $\mathrm{F}_{5}$ and $\mathrm{F}_{8}$ niosomal gels containing $0.1 \mathrm{mg} \mathrm{BMV}$ was placed into each donor compartment and sealed for providing occlusive conditions [47].

Aliquots of receptor medium ( $1 \mathrm{ml}$ ) were withdrawn at different time intervals; 1, 2, 4, 6 , and 24 hours and replaced by the same fresh medium volume. The amount of drug permeated through the skin was determined spectrophotometrically at $243.3 \mathrm{~nm}$ (Shimadzu, Model 2401, Japan) $[26,36,48]$. UV method was validated for linearity and precision (intra and interday) for the range used $(2-10 \mu \mathrm{g} / \mathrm{ml})$. The limit of quantification ( $\mathrm{LOQ}=0.185 \mu \mathrm{g} / \mathrm{ml})$ and the limit of detection ( $\mathrm{LOD}=0.061 \mu \mathrm{g} / \mathrm{ml}$ ) were calculated according to the guidelines of the International Conference for Harmonization [49].

Permeation profiles were constructed by plotting the cumulative percentage of BMV permeated versus time. The steady-state flux (Jss, $\mu \mathrm{g} / \mathrm{cm}^{2} / \mathrm{h}$ ) was computed using linear regression analysis. Permeability coefficient $(\mathrm{Kp})$ was determined by dividing the flux by initial drug concentration ( $\mathrm{Co}$ ) in the donor compartment and was expressed as [50]:

$$
\mathrm{Kp}=\frac{\mathrm{Jss}}{\mathrm{Co}}
$$

Penetration enhancement was determined in terms of enhancement ratio (ER) according to this relation [51]:

$$
\mathrm{ER}=\frac{\text { Jss of formulation }}{\text { Jss of control }}
$$

To predict the mechanism by which BMV is permeated from niosomal formulations, the data were analyzed to find the best fitting kinetic model.

\subsubsection{In-vivo anti-inflammatory efficacy.}

Anti-inflammatory efficacy and sustaining the action of niosomal gels were investigated using the carrageenan-induced hind paw edema method [52] and compared with that of BMV plain gel and marketed product.

\subsubsection{Experimental design.}

Adult male Wister albino rats (130-180 g) were purchased from the animal breeding house of the National Research Center, Dokki, Giza, Egypt. They were housed in clean rat 
cages (10 rats) and kept under standard controlled conditions of temperature $\left(21-24^{\circ} \mathrm{C}\right)$ and relative humidity (40-60\%) with alternating 12 hours dark-light cycles. Animals were fed with a chow diet and water ad libitum and were acclimatized for 14 days prior to experimentation.

The protocol of the study was approved by the Ethics Committee of Faculty of Pharmacy, Cairo University (approval number PI-1609) and the Medical Research Ethics Committee of National Research Centre, Giza, Egypt (approval number 15228).

\subsubsection{Carrageenan-induced paw edema.}

For induction of edema, carrageenan suspension $(0.1 \mathrm{ml}$ of $1 \% \mathrm{w} / \mathrm{v}$, in saline) was injected into the sub plantar surface of the right hind paw. The contralateral paw received an equal volume of saline [52]. Rats were randomly divided into five groups, each of five animals as follows: group I representing non-treated rats which received normal saline $(0.2 \mathrm{ml} / \mathrm{rat})$ and served as a positive control, group II representing rats treated by topical application of $\mathrm{F}_{5}$ niosomal gel, group III representing rats treated by topical application of F8 niosomal gel, group IV representing rats treated by topical application of the marketed product and finally group $\mathrm{V}$ representing rats treated by topical application of BMV plain gel. Formulations were applied to the plantar surface of the right hind paw [36] at a dose level of $1 \mathrm{mg} / \mathrm{kg}$ [53] by gentle rubbing, half an hour before induction of inflammation. Oedema component was quantified by measuring the difference in hind paw thickness with a micrometer caliper before carrageenan injection and after carrageenan injection by 1,2,3,4 and 24 hours [54, 55].

Percentage of paw swelling was determined according to this relation [56]:

$$
\% \text { Swelling }=\frac{(\mathrm{V}-\mathrm{Vi})}{\mathrm{Vi}} \mathrm{x} 100
$$

Where, $\mathrm{V}$ is the thickness of the paw at each time interval, and $\mathrm{V}_{\mathrm{i}}$ is the initial thickness of the paw before carrageenan injection. Percentage of edema inhibition in the drug-treated rats was calculated in terms of this equation [56]:

$$
\% \text { Inhibition }=\left[1-\frac{\% \text { swelling treated }}{\% \text { swelling control }}\right] \times 100
$$

Where, swelling treated is the mean value computed in the treated group, and swelling control is the mean value computed in the control group [57].

\subsubsection{Histopathological examination of paw tissue.}

The anti-inflammatory effect of BMV niosomal formulations was also evaluated by histological assessment. One rat from each group was sacrificed by cervical dislocation, 4 hours after edema induction [58]. Tissue slices were excised, dipped in 10\% formalin-saline, dehydrated in graded concentrations of ethanol, dipped in xylene, and inserted in a paraffin block. The skin was cut, stained with hematoxylin-eosin (H \& E) [59], and examined microscopically by a light microscope.

\subsubsection{Data analysis and statistics.}

Studies were performed in triplicate, and results were presented as a mean \pm standard deviation (S.D.). SPSS software (version 22.0; IBM Co., USA) was used for data analysis, and means were compared using one-way analysis of variance (ANOVA) followed by least- 
significant difference test (LSD). Differences were considered statistically significant when the p-value was less than 0.05 .

\section{Results and discussion}

\subsection{Characterization of BMV-loaded niosomes.}

\subsubsection{Entrapment efficiency (EE \%).}

Results presented in Table 1 showed that the addition of DCP to $F_{2}, F_{5}, F_{8}$, and $F_{11}$ enhanced entrapment efficiency, which ranged between $85.01 \pm 2.72$ and $92.03 \pm 1.88 \%$ as they showed an increase in entrapment efficiencies values, but this increase was statistically nonsignificant $(\mathrm{p}>0.05)$ when compared to niosomal formulations prepared without adding any charge inducers; $F_{1}, F_{4}, F_{7}$, and $F_{10}$. This might be attributed to the increase in the distance between adjoining lamellar bilayers due to electrostatic repulsion between adjacent bilayers, resulting in entrapment of larger amounts of the drug [60]. However, formulations prepared using $\mathrm{SA} ; \mathrm{F}_{3}, \mathrm{~F}_{6}, \mathrm{~F}_{9}$, and $\mathrm{F}_{12}$, showed the lowest values ranged between $14.44 \pm 1.91$ and 38.12 $\pm 2.99 \%$. The incorporation of SA into niosomes resulted in a significant decrease $(p<0.05)$ in the amount of BMV entrapped. This could be explained by the formation of low stability niosomal system in which particle aggregation was observed during the preparation, as reported previously [43].

Moreover, Table 1 showed non-significant increase ( $p>0.05)$ in BMV entrapment efficiency upon increasing CHOL content from 33 mole $\%\left(\mathrm{~F}_{4}, \mathrm{~F}_{5}, \mathrm{~F}_{6}, \mathrm{~F}_{10}, \mathrm{~F}_{11}, \mathrm{~F}_{12}\right)$ to 50 mole\% $\left(\mathrm{F}_{1}, \mathrm{~F}_{2}, \mathrm{~F}_{3}, \mathrm{~F}_{7}, \mathrm{~F}_{8}, \mathrm{~F}_{9}\right)$. CHOL increases the hydrophobicity of bilayer structure [61], decreases its permeability [62], and can enhance the stability and entrapment of the hydrophobic drug BMV into the lipid bilayers. This finding was following some previous studies [63, 64].

\subsubsection{Vesicle size, polydispersity index, and Zeta-potential.}

Niosomal formulations exhibited a mean vesicle size ranging from 123.1 to $782 \mathrm{~nm}$ as presented in Table 1. The inclusion of CIA into niosomes resulted in a significant increase in vesicle size $(\mathrm{p}<0.05)$. The incorporation of DCP caused the separation of adjacent bilayers due to charge repulsion, which increased aqueous compartment volume, leading to an increase in vesicle size [65]. In niosomal formulations containing SA, the effect was more pronounced as they exhibited the largest particle size among all formulations. This might be due to the aggregations formed as a result of SA-induced zeta-potential reduction, as previously reported [29].

CHOL content had an apparent impact on vesicle size (Table 1). It was found that increasing CHOL concentration from 33 mole $\%$ to 50 mole $\%$ led to a significant increase in vesicle size $(\mathrm{p}<0.05)$. This could be attributed to vesicular membrane disruption resulting from hydrophobicity increase in the presence of higher CHOL content which subsequently increased vesicle radius to produce a more thermodynamically stable form leading to the formation of larger vesicles with greater thermodynamic stability [66].

Also, it was noticed that niosomes prepared using Span 40 had significantly larger vesicle size $(\mathrm{p}<0.05)$ than niosomes prepared with Span 60. Surface free energy increases as hydrophobicity decrease [67]; hence, less hydrophobic surfactants should yield larger vesicles which rationalized the greater size of Span 40 based niosomes, since HLB value of Span 40 is 6.7 and that of Span 60 is 4.7 [68]. 
It was observed that PDI values of the prepared formulations were high $(>0.3)$ (Table 1), suggesting a heterogeneous population that is generally obtained with niosomes prepared by thin-film hydration technique not accompanied by vesicles sonication or extrusion [69].

Zeta potential was measured as charged niosomes are generally more stable against aggregation and fusion [70]. It was found that $F_{1}, F_{2}, F_{4}, F_{5}, F_{7}, F_{8}, F_{10}$, and $F_{11}$ had large negative values ranging between $-34 \mathrm{mv}$ and $-54.6 \mathrm{mv}$ (Table 1), indicating good stability. Negative values of zeta-potential for niosomes, prepared without adding any CIA; could be due to preferential hydroxyl ions adsorption or counter ions adsorption at the surface of vesicles [71] and are sufficiently high for electrostatic stabilization. The incorporation of DCP resulted in higher negative values of zeta-potential and led to the formation of a more stable colloidal system. However, the effect of incorporating SA into the formulations was noticed as it neutralized the negative surface charges, which lowered the values of zeta-potential and subsequently caused the aggregation of vesicles, indicating low stability of these systems as previously stated [43].

\subsubsection{Transmission electron microscopy (TEM).}

TEM studies were performed to get an insight into the morphology of the investigated niosomal formulations. Figure 1 demonstrated electron micrographs of $\mathrm{F}_{1}, \mathrm{~F}_{2}, \mathrm{~F}_{4}, \mathrm{~F}_{5}, \mathrm{~F}_{7}, \mathrm{~F}_{8}, \mathrm{~F}_{10}$ and $F_{11}$. Vesicles are well identified, almost spherical in shape, having a definite smooth vesicle surface enclosing an internal aqueous core [72]. Figure 1 also revealed micrographs of $F_{3}, F_{6}$, $\mathrm{F}_{9}$, and $\mathrm{F}_{12}$, where the effect of adding $\mathrm{SA}$ to the formulation was noticed, showing heavily stained vesicles with irregular boundaries and no definite shape or structure. SA neutralized negative charges carried by niosomes leading to decreased repulsion forces between the vesicles and a subsequent aggregation [43].
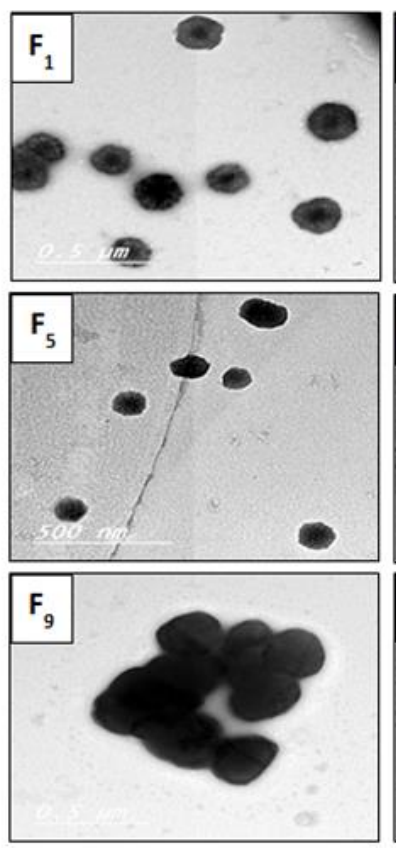
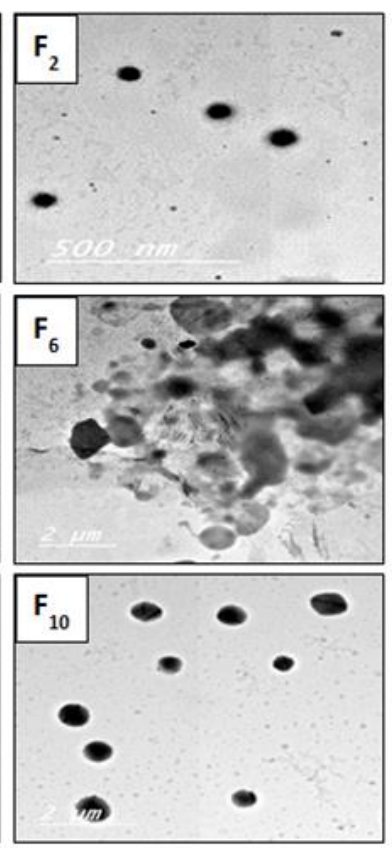
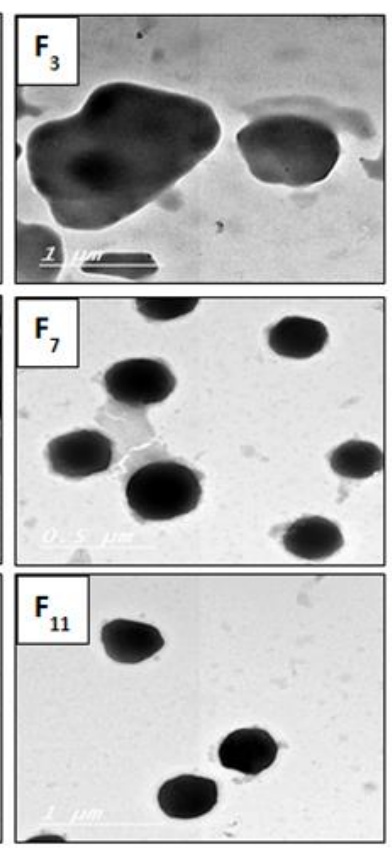
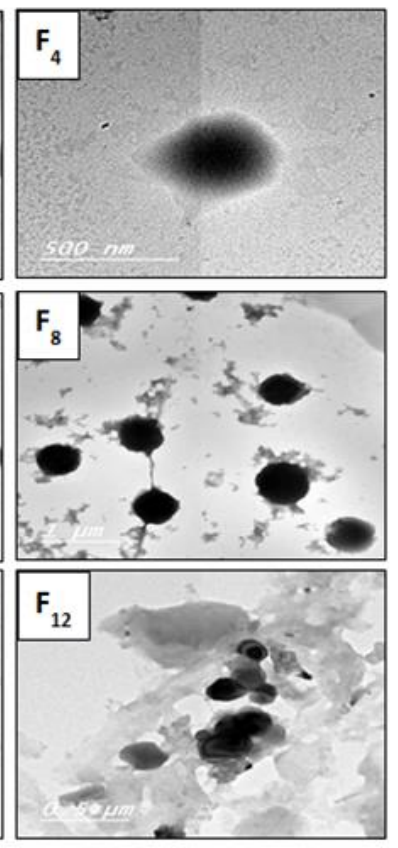

Figure 1. TEM Micrographs of different betamethasone valerate niosomal formulations.

\subsection{In-vitro release studies of BMV niosomes.}

Figure 2 demonstrated BMV release pattern from different niosomal formulations and from its free suspension for comparison. The release pattern of BMV occurred in two phases, 
an initial relatively rapid release phase lasting for 8 hours where more than $50 \%$ of entrapped BMV was released, followed by a steady phase with slower and reduced release rate, which is maintained for 96 hours, and more than $90 \%$ of the drug was released. This biphasic release pattern agrees with previously stated studies and appears to be a general feature of bilayer vesicles $[73,74]$. The rapid drug release might be due to the release of drug adsorbed on the hydrophilic head of vesicles, helping to achieve the optimum loading dose of the drug [75] while the slower phase could be mainly attributed to drug diffusion through the bilayers [76]. Thus, niosomes can be considered to be nano-drug depots capable of controlling and prolonging the release of drugs [77]. This was confirmed when comparing the data obtained from the release study of BMV from its free suspension, where more than $90 \%$ of the drug was released within 6 hours. Both phases are of interest for dermal application, in which moderate release is beneficial to enhance drug penetration for faster onset of action, whereas sustainedrelease supplies the drug through an extended time period reducing application time and lowering toxicity $[78,79]$.

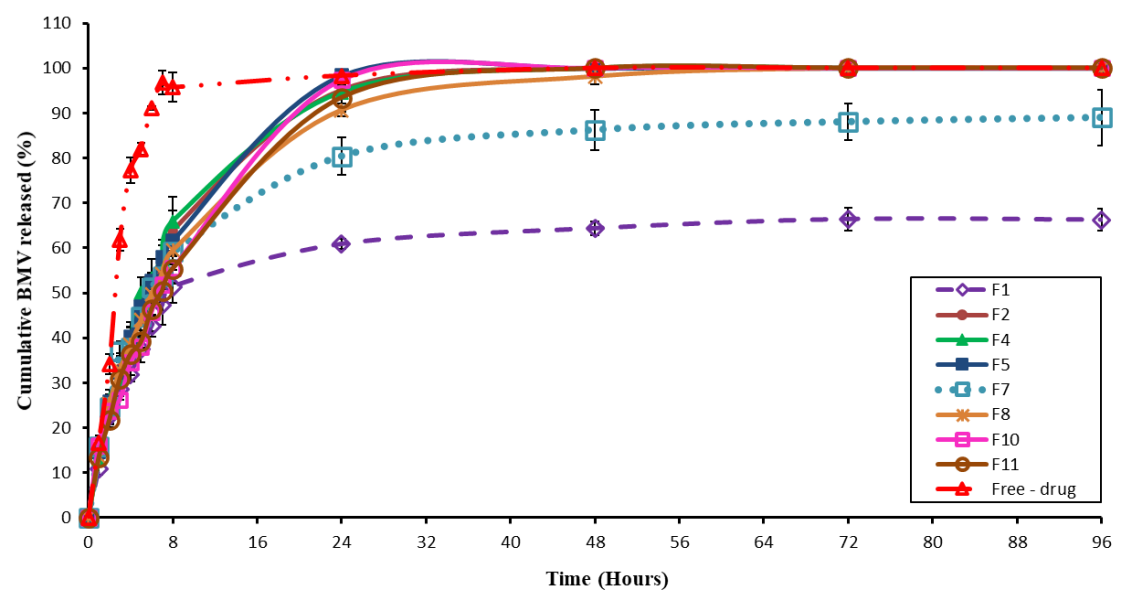

Figure 2. In-vitro release profiles of different betamethasone valerate niosomal formulations $(\mathrm{n}=3)$.

The effect of DCP on release rates of BMV from niosomes was clear, where niosomal formulations containing DCP showed relatively higher release rate constants compared to their corresponding niosomes prepared without adding any charge inducer (Table 2). This could be due to the increase in electrostatic repulsion force between intra niosomal bilayers resulting from the inclusion of DCP, which facilitates the permeation of entrapped BMV into the release medium [80]. Also, increasing CHOL content from 33 mole $\%$ to 50 mole $\%$ reduced the efflux of BMV except for $\mathrm{F}_{2}$, which showed a nearly similar release rate constant compared to $\mathrm{F}_{5}$ (9.77 and $9.6 \mathrm{mgh}^{-1 / 2}$, respectively). These results agree with CHOL's previously stated ability to stabilize membranes and fill pores in the vesicular bilayer $[73,81]$, which helps to sustain drug release from niosomes [80].

In-vitro release profiles were treated with different mathematical models, and results are illustrated in Table 2. The drug's release pattern from all formulations and from its free suspension followed the Higuchi equation as indicated from the highest correlation coefficient $\left(\mathrm{R}^{2}\right)$. These findings are typically following previous works reporting that drug-loaded niosomes have a controlled release pattern following Higuchi's square root model [80]. Korsmeyer-Peppas model indicated that all the diffusional exponent (n) values were below 0.45, demonstrating that BMV release from niosomes follows Fickian diffusion without erosion of vesicles [34]. 
Table 2. Release kinetics of betamethasone valerate niosomal formulations $(n=3)$.

\begin{tabular}{l|c|c|c|c|c|c|c|c} 
Formula & \multicolumn{3}{c}{$\mathbf{R}^{\mathbf{2}}$} & $\begin{array}{c}\text { Release rate } \\
\text { constant }\left(\mathbf{m g h}^{-1 / 2}\right)\end{array}$ & \multicolumn{3}{c}{ Korsmeyer-Peppas parameters } \\
& $\begin{array}{l}\text { Zero } \\
\text { Order }\end{array}$ & $\begin{array}{c}\text { First } \\
\text { Order }\end{array}$ & $\begin{array}{c}\text { Higuchi } \\
\text { Diffusion model }\end{array}$ & & $\mathbf{R}^{\mathbf{2}}$ & $\mathbf{K}$ & $\mathbf{N}$ & $\begin{array}{c}\text { Release } \\
\text { mechanism }\end{array}$ \\
\hline $\mathrm{F}_{1}$ & 0.5860 & 0.4015 & $\mathbf{0 . 7 4 6 1}$ & 5.38 & 0.794 & 19.05 & 0.33 & Fickian diffusion \\
\hline $\mathrm{F}_{2}$ & 0.6717 & 0.4949 & $\mathbf{0 . 8 2 8 7}$ & 9.77 & 0.881 & 19.9 & 0.41 & Fickian diffusion \\
\hline $\mathrm{F}_{4}$ & 0.6550 & 0.4680 & $\mathbf{0 . 8 1 4 2}$ & 9.53 & 0.858 & 21.37 & 0.40 & Fickian diffusion \\
\hline $\mathrm{F}_{5}$ & 0.6585 & 0.4962 & $\mathbf{0 . 8 1 7 9}$ & 9.6 & 0.882 & 21.37 & 0.39 & Fickian diffusion \\
\hline $\mathrm{F}_{7}$ & 0.6762 & 0.4976 & $\mathbf{0 . 8 2 9 9}$ & 7.8 & 0.877 & 22.9 & 0.34 & Fickian diffusion \\
\hline $\mathrm{F}_{8}$ & 0.7101 & 0.5208 & $\mathbf{0 . 8 6 0 1}$ & 9.7 & 0.896 & 20.41 & 0.41 & Fickian diffusion \\
\hline $\mathrm{F}_{10}$ & 0.6998 & 0.5757 & $\mathbf{0 . 8 4 9 0}$ & 10.24 & 0.927 & 19.05 & 0.41 & Fickian diffusion \\
\hline $\mathrm{F}_{11}$ & 0.7136 & 0.5489 & $\mathbf{0 . 8 6 2 4}$ & 10.18 & 0.916 & 18.62 & 0.42 & Fickian diffusion \\
\hline Free BMV & 0.2541 & 0.1798 & $\mathbf{0 . 3 8 9 1}$ & 5.94 & 0.534 & 38.01 & 0.28 & Fickian diffusion
\end{tabular}

\subsection{Physical stability study.}

$\mathrm{F}_{4}, \mathrm{~F}_{5}, \mathrm{~F}_{8}$, and $\mathrm{F}_{10}$, exhibited good physical stability, with no color change, sedimentation, coarse particles, or layer separation. There was no significant decrease in drug content ( $\mathrm{p}<0.05$ ) over 3 months, as demonstrated in Table 3. This could be due to CHOL's presence in the vesicular bilayers having the ability to stabilize membranes, reducing drug leakage to a great extent [43]. The storage temperature of $5^{\circ} \mathrm{C}$ was proven to be more suitable for reducing drug leakage from niosomal vesicles, as proved in another study [82]. Table 3 also shows vesicle sizes over 3 months of storage compared to their size at the experiment's initial time. Results revealed a significant increase $(\mathrm{p}<0.05)$ in vesicle sizes of all formulations after storage (Table 3), in the range of 448 to $659 \mathrm{~nm}$. This could be due to the previously reported fusion and aggregation of niosomal vesicles after storage [83].

Table 3. Mean drug retained and mean vesicle size of betamethasone valerate niosomal formulations stored at

\begin{tabular}{|c|c|c|c|c|c|c|c|c|}
\hline & \multicolumn{2}{|c|}{$\mathbf{F}_{4}$} & \multicolumn{2}{|c|}{$F_{5}$} & \multicolumn{2}{|l|}{ 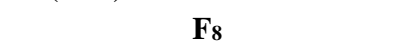 } & \multicolumn{2}{|c|}{$F_{10}$} \\
\hline $\begin{array}{l}\text { Time } \\
\text { (days) }\end{array}$ & $\begin{array}{l}\text { Drug retained } \\
\qquad(\%) \pm \text { S.D. }\end{array}$ & $\begin{array}{c}\text { Mean } \\
\text { vesicle size } \\
(\mathrm{nm}) \pm \text { S.D. }\end{array}$ & $\begin{array}{l}\text { Drug retained } \\
\qquad(\%) \pm \text { S.D. }\end{array}$ & $\begin{array}{c}\text { Mean vesicle } \\
\text { size (nm) } \\
\text { 土S.D. }\end{array}$ & $\begin{array}{l}\text { Drug retained } \\
\qquad(\%) \pm \text { S.D. }\end{array}$ & $\begin{array}{c}\text { Mean vesicle } \\
\text { size }(\mathrm{nm}) \\
\pm \text { S.D. }\end{array}$ & $\begin{array}{c}\text { Drug retained } \\
(\%) \pm \text { S.D. }\end{array}$ & $\begin{array}{c}\text { Mean vesicle } \\
\text { size }(\mathrm{nm}) \\
\text { 土S.D. }\end{array}$ \\
\hline Initial & $100 \pm 0.00$ & $108 \pm 13.4$ & $100 \pm 0.00$ & $132 \pm 8.48$ & $100 \pm 0.00$ & $461 \pm 29.39$ & $100 \pm 0.00$ & $106 \pm 19.79$ \\
\hline 90 days & $88.92 \pm 1.73$ & $493 \pm 70.5$ & $81.86 \pm 2.6$ & $448 \pm 61.2$ & $82.07 \pm 0.41$ & $659 \pm 88.71$ & $89.13 \pm 3.7$ & $550 \pm 82.02$ \\
\hline
\end{tabular}

\subsection{Evaluation of BMV niosomal gel.}

\subsubsection{Spreadability.}

The prepared gels must have a good spreadability to ensure a uniform application to the skin [84]. Spreadability values, presented in Table 4, demonstrated that the spreadability of $F_{5}$ and $\mathrm{F}_{8}$ niosomal gels was comparable with that of commercial products and fulfilled the ideal quality in topical application.

Table 4. pH, spreadability values, rheological behavior, in-vitro skin permeation parameters of selected niosomal gels $\left(\mathrm{F}_{5}\right.$ and $\left.\mathrm{F}_{8}\right)(\mathrm{n}=3)$.

\begin{tabular}{|c|c|c|c|c|c|c|c|}
\hline Formulations & pH & $\begin{array}{c}\text { Spreading } \\
\text { diameter } \\
(\mathrm{mm}) \pm \text { S.D. }\end{array}$ & $\begin{array}{l}\text { Farrow's } \\
\text { constant } \\
\text { (n) }\end{array}$ & $\begin{array}{c}\text { Hysteresis } \\
\text { area }\left(\text { Pa.s }^{-1}\right)\end{array}$ & $\begin{array}{c}\text { Steady-state } \\
\text { flux } \pm \text { S.D. } \\
\left(\mu \mathrm{g} / \mathrm{cm}^{2} / \mathrm{hr}\right)\end{array}$ & $\begin{array}{c}\text { Permeation coefficient } \\
\pm \text { S.D. }(\mathrm{cm} / \mathrm{hr})\end{array}$ & $\begin{array}{c}\text { Enhancement ratio } \\
\pm \text { S.D. }\end{array}$ \\
\hline$F_{5}$ niosomal gel & 5.74 & $40 \pm 2.06$ & 4.3313 & 11364.5 & $0.299 \pm 0.057$ & $2.99 \times 10^{-3} \pm 0.573 \times 10^{-3}$ & $1.24 \pm 0.08$ \\
\hline F8 niosomal gel & 5.78 & $35 \pm 1.15$ & 4.9192 & 3209.5 & $0.271 \pm 0.091$ & $2.71 \times 10^{-3} \pm 0.91 \times 10^{-3}$ & $1.11 \pm 0.21$ \\
\hline BMV plain gel & - & - & - & - & $0.241 \pm 0.0067$ & $2.41 \times 10^{-3} \pm 0.067 \times 10^{-3}$ & - \\
\hline
\end{tabular}




\begin{tabular}{l|c|c|c|c|c|c|c} 
Formulations & $\mathbf{p H}$ & $\begin{array}{c}\text { Spreading } \\
\text { diameter } \\
(\mathbf{m m}) \pm \text { S.D. }\end{array}$ & $\begin{array}{c}\text { Farrow's } \\
\text { constant } \\
(\mathbf{n})\end{array}$ & $\begin{array}{c}\text { Hysteresis } \\
\text { area }\left(\mathbf{P a . s}^{-1}\right)\end{array}$ & $\begin{array}{c}\text { Steady-state } \\
\text { flux } \mathbf{\pm S . D .} \\
\left(\boldsymbol{\mu g} / \mathbf{c m}^{\mathbf{2}} / \mathbf{h r}\right)\end{array}$ & $\begin{array}{c}\text { Permeation coefficient } \\
\pm \text { S.D. }(\mathbf{c m} / \mathbf{h r})\end{array}$ & $\begin{array}{c}\text { Enhancement ratio } \\
\pm \text { S.D. }\end{array}$ \\
\hline Marketed gel 1 & - & $37 \pm 1.15$ & - & - & - & - & - \\
\hline Marketed gel 2 & - & $43 \pm 1.52$ & - & - & - & - & -
\end{tabular}

\subsection{2. $\mathrm{pH}$ measurement.}

$\mathrm{pH}$ values of niosomal gels were found to be 5.74 for F5 gel and 5.78 for F8 gel. Both gels seem non-irritating to the skin as the measured $\mathrm{pH}$ values were within the physiological skin $\mathrm{pH}$ range, i.e., 4 to 6 [37].

\subsubsection{Rheological behavior.}

The rheological behavior of gels was evaluated to predict their suitability for topical application [85, 86], as gel viscosity influences its spreadability and adherence to the skin surface [87] and has an impact on the drug release rate [88].

The rheograms, presented in Figure 3, revealed that the shear stress was not directly proportional to a shear rate approaching the origin with no yield values, indicating nonNewtonian flow behavior. The ascending and descending flow curves almost overlapped with a very narrow deformation at the end of the descending period, verifying shear-thinning system behavior, i.e., pseudoplastic flow with thixotropic behavior [38]. This was confirmed by the characteristic bend in the viscosity curves (Figure 3) and Farrow's constant (n) values larger than one (Table 4), indicating a pseudoplastic flow behavior of the niosomal gels [89]. The calculated hysteresis area (H.A.) values confirmed a degree of thixotropy of the prepared niosomal gels (Table 4). This behavior is preferred in pharmaceutical gels [90] because when applying a certain force, the viscosity decrease ensuring good spreadability, and at the same time, the gel remains at the site of application and does not continue to flow over it [91].

F 5 niosomal gel
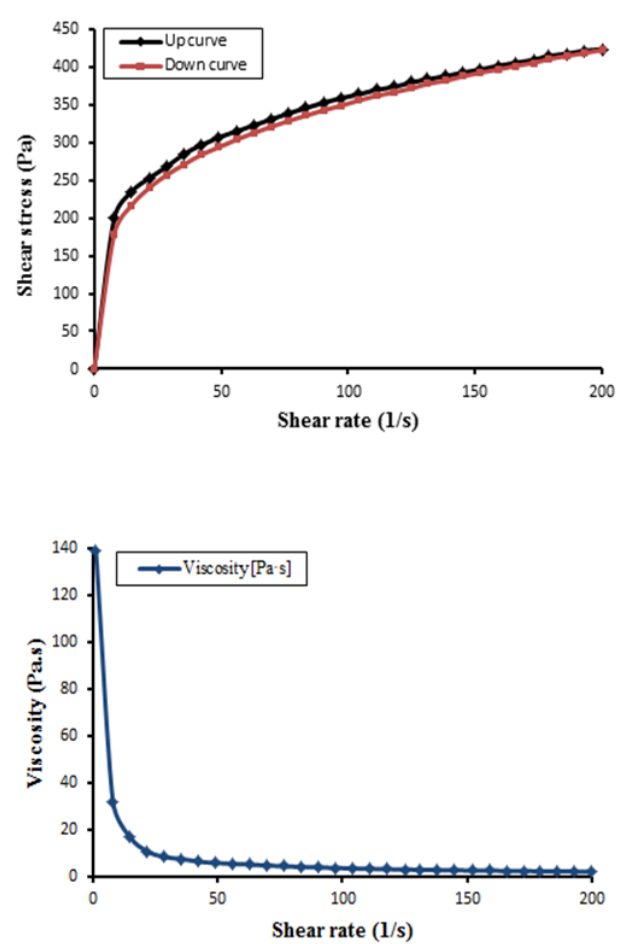

F8 niosomal gel
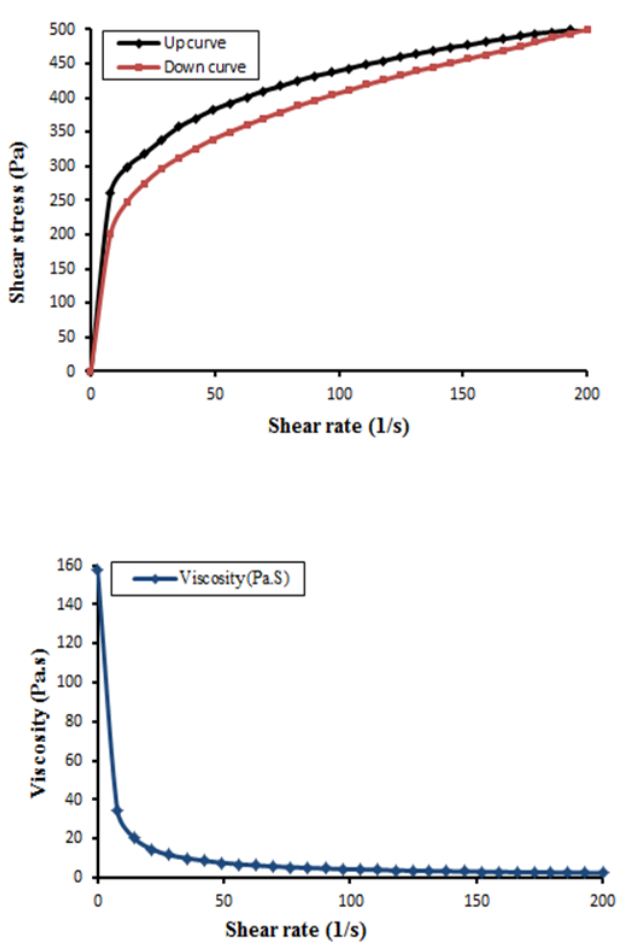

Figure 3. Rheograms of $F_{5}$ and $F_{8}$ niosomal gels demonstrating shear rate vs. shear stress and viscosity vs. shear rate plots. 
This could be due to the structural breakdown of the intermolecular interactions between polymeric chains as shear stress is increased, and after the elimination of shearing force, polymerization is reoccurred due to van der Waal interaction forces between molecules of the polymer [90].

The rheological behavior exhibited by the prepared gels fulfilled the ideal criteria for topical application.

\subsection{Ex-vivo permeation studies.}

Figure 4 shows permeation profiles of BMV from the plain gel and from niosomal gel formulations. Results show the superiority of permeation of BMV encapsulated in the niosomal formulations $\mathrm{F}_{5}$ and $\mathrm{F}_{8}$ over BMV plain gel.

In-vitro permeation parameters, steady-state flux (Jss), permeability coefficient (Kp), and enhancement ratio (ER) of niosomal and non-niosomal formulations are presented in Table 4. It can be observed that niosomal gels showed higher skin permeation of BMV as indicated by the increased flux and permeability coefficient values. F5 niosomal gel exhibited the highest steady-state flux ( Jss $=0.299 \pm 0.057 \mu \mathrm{g} / \mathrm{cm}^{2} / \mathrm{hr}$ ) followed by F8 niosomal gel having a steadystate flux value of $0.271 \pm 0.091 \mu \mathrm{g} / \mathrm{cm}^{2} / \mathrm{hr}$. The Lower flux value was obtained using BMV plain gel ( Jss $\left.=0.241 \pm 0.0067 \mu \mathrm{g} / \mathrm{cm}^{2} / \mathrm{hr}\right)$, which revealed the permeation-enhancing effect of vesiculation on the drug. Statistical analysis of flux values confirmed that the two niosomal gels exhibited statistically significant improvement in permeation when compared to BMV plain gel $(\mathrm{p}<0.05)$.

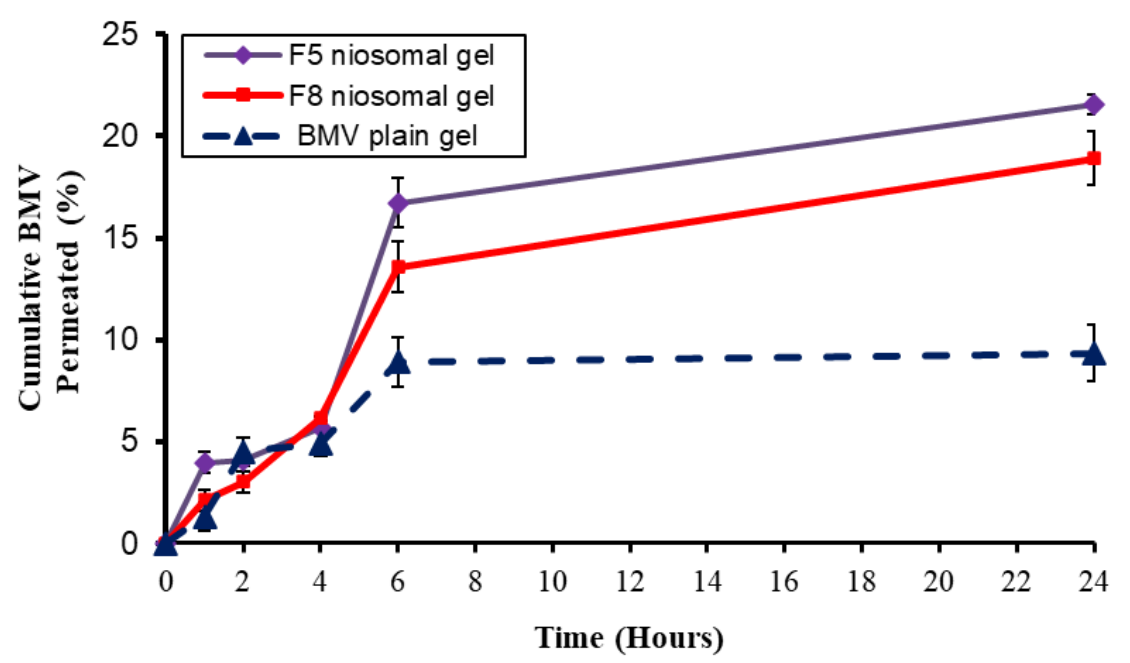

Figure 4. Permeation profiles of betamethasone valerate from niosomal gels, and plain gel through mouse $\operatorname{skin}(n=3)$.

The ability of niosomes to enhance percutaneous permeation of the drug could be explained by several mechanisms, including; adsorption and fusion of vesicles on the skin surface, niosomal vesicles may act as penetration enhancers reducing the barrier properties of stratum corneum as the intercellular lipid barrier would be significantly looser and more permeable after treatment with niosomes [92, 93].

These findings suggest that the developed BMV-loaded niosomes were effective and promising for carrying the drug into deeper layers of the skin which can enhance skin retention, minimize side effects induced by systemic absorption as a small amount of BMV 
approximately $7 \mu \mathrm{g} / \mathrm{cm}^{2}$ permeated through the skin, after 24 hours of treatment with niosomal formulations.

This was in agreement with other studies' findings indicating greater drug deposition into the skin when drug-containing vesicular systems are used [18, 94].

Drug permeation kinetics studies showed that permeation of BMV through the skin from the two niosomal formulations and from BMV plain gel is most fitted to the diffusioncontrolled mechanism (Higuchi's model), as diffusion out of vesicles displayed the highest $\mathrm{R}^{2}$ values (data are not shown). Results also revealed sustained release characteristics with the Higuchi pattern of drug release, where niosomes act as a depot for continuous drug delivery. These findings are following previous reports $[38,95]$.

\subsection{In-vivo anti-inflammatory efficacy.}

3.6.1. Carrageenan-induced paw edema.

Findings of ex-vivo studies were further confirmed by in-vivo studies. The antiinflammatory effect of $\mathrm{F}_{5}$ and $\mathrm{F}_{8}$ niosomal gels were compared with that of BMV plain gel and marketed product using carrageenan-induced hind paw edema method [52]. Results were calculated as a percentage of edema inhibition, recorded in Table 5 and presented in Figure 5.

Table 5. Effect of different formulations on rat paw edema (\% edema inhibition) $(n=3)$.

\begin{tabular}{l|c|c|c|c|c|}
\hline Groups & \multicolumn{5}{|c|}{ Edema inhibition (\%) } \\
\hline & 1 hour & 2hours & 3 hours & 4 hours $^{@}$ & 24 hours \\
\hline F5 niosomal gel & $59.17 \pm 4.99^{@}$ & $42.48 \pm 4.86$ & $61.57 \pm 5.23^{@}$ & $76.81 \pm 4.56^{@ \$}$ & $69.05 \pm 0.586^{@ \$}$ \\
\hline F8 niosomal gel & $42.77 \pm 3.87$ & $36.94 \pm 3.14$ & $55.09 \pm 5.78^{@}$ & $65.58 \pm 4.37^{@}$ & $60.85 \pm 0.99^{@}$ \\
\hline Marketed product & $48.88 \pm 3.64$ & $37.5 \pm 3.83$ & $38.67 \pm 3.63$ & $42.99 \pm 3.1$ & $50.3 \pm 0.92^{@}$ \\
\hline BMV plain gel & $38.74 \pm 3.73$ & $33.77 \pm 3.77$ & $23.98 \pm 1.84$ & $22.51 \pm 2.06$ & $31.47 \pm 2.61$ \\
\hline
\end{tabular}

${ }^{\circledR}$ significant difference from BMV plain gel group at $\mathrm{p}<0.05$

$\$$ significant difference from marketed product group at $\mathrm{p}<0.05$

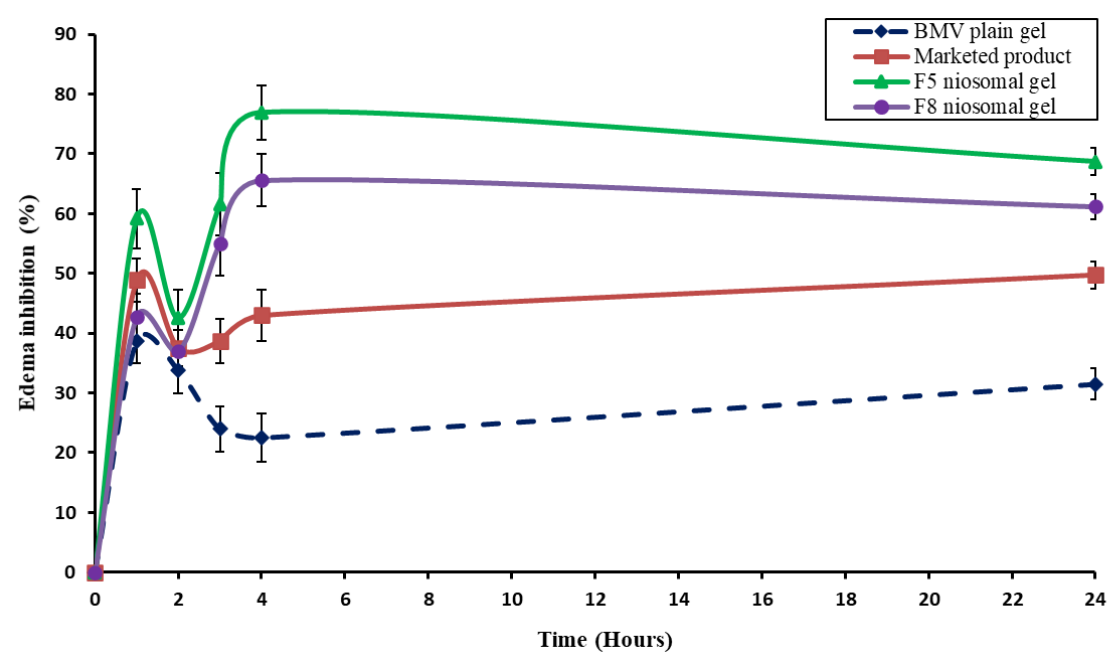

Figure 5. Edema inhibition (\%) caused by the application of different formulations $(n=3)$.

Initially, the group treated with BMV plain gel showed edema inhibition \% of $38.74 \%$ \pm 9.73 at the first hour, then the effect was reduced with time reaching $31.47 \% \pm 2.61$ after 24 hours. In the case of $\mathrm{F}_{5}$ and $\mathrm{F}_{8}$ niosomal gel groups, edema inhibition $\%$ was higher than both drug plain gel and marketed product groups at almost all test points. The $\%$ inhibition gradually increased with time to reach $76.81 \% \pm 4.56\left(\mathrm{~F}_{5}\right)$ and $65.58 \% \pm 4.37\left(\mathrm{~F}_{8}\right)$ at the $4^{\text {th }}$ hour then the effect was sustained to reach $69.05 \% \pm 0.586\left(\mathrm{~F}_{5}\right)$ and $60.85 \% \pm 0.99$ (F8) after 24 hours. 
Analysis of data using one-way ANOVA followed by LSD test for multiple comparisons revealed that $\mathrm{F}_{5}$ and $\mathrm{F}_{8}$ produced significant inhibitory effect on paw edema compared to BMV plain gel $(\mathrm{p}<0.05)$ starting from the $3^{\text {rd }}$ hour, and the effect was sustained for a longer time (up to 24 hours). Moreover, the anti-inflammatory activity of $F_{5}$ was significantly higher than the marketed product $(\mathrm{p}<0.05)$ at the $4^{\text {th }}$ and the $24^{\text {th }}$ hours, but there was no significant difference between the anti-inflammatory effect of $\mathrm{F}_{8}$ and the marketed product.

The prolonged and enhanced anti-inflammatory activity of both niosomal gels could be attributed to the superior skin penetration [96] and higher skin retention [97] of niosomal drug, which indicated depot forming properties of niosomal gel [20], offering sustained drug release from niosomes for an extended period of time, reaching at least 24 hours, for edema reduction [98]. Jaafari et al. previously mentioned that vesicles, in the proper formulations and sizes, we're able to pass through the stratum corneum, reach the epidermis and deep dermis, as the electron microscopy studies had revealed the presence of intact niosomes in the epidermis and dermis [99].

\subsubsection{Histopathological examination of paw tissue.}

Microscopic study of paw biopsies of non-treated rats showed acute inflammation with massive accumulation of infiltrated inflammatory cells in the connective tissue. Congestion of blood vessels and blood capillary dilatation was observed in the papillary dermis. Diffused large edematous areas were noticed in the reticular dermis and the underlying hypodermis, as shown in Figure 6A.
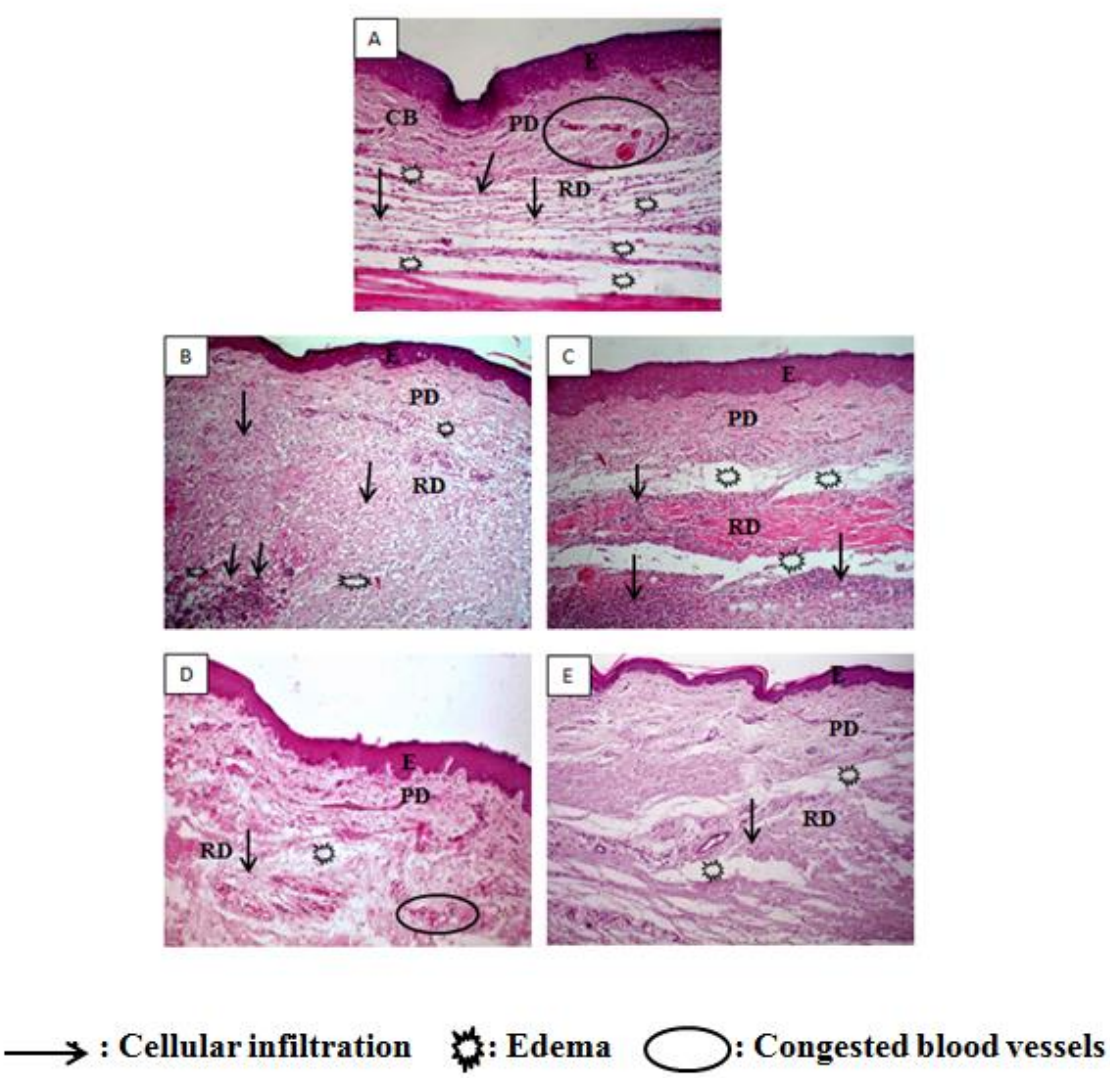

Figure 6. Histopathological examination of rat paw tissue obtained from; (A) positive control group, (B) BMV plain gel group, (C) marketed product group, (D) $\mathrm{F}_{5}$ niosomal gel group, (E) $\mathrm{F}_{8}$ niosomal gel group. Epidermis (E), papillary dermis (PD), and reticular layers (RD) (H\&E× 100). 
Paw biopsies of animals treated with BMV plain gel showed a slight improvement in inflammation as edema is slightly inhibited, but diffuse cellular infiltration was still noticed in all skin layers (Figure 6B).

Figure $6 \mathrm{C}$ revealed a photomicrograph of rat skin treated with the marketed product showing nearly normal superficial papillary layer, but heavy cellular infiltration and wide edematous areas were still noticed in the other deeper dermal layers, which indicated superficial improvement only in this group.

Interestingly, topical treatment with $\mathrm{F}_{5}$ and $\mathrm{F}_{8}$ niosomal gels drastically diminished the inflammatory response in carrageenan-induced rat paw edema. Inflammatory cells were reduced in number compared to the positive control group, as shown in Figures 6D and E where only a few scattered inflammatory cells were observed. Some small edematous areas were also noticed, and a remarkable decrease in blood congestion was also revealed, which indicated a significant anti-inflammatory effect of niosomal formulations.

Taking these data together, we can conclude that $\mathrm{F}_{5}$ and $\mathrm{F}_{8}$ niosomal gels considerably reduced morphological injury and cellular infiltration in rat paw skin and were more effective than both BMV plain gel and marketed products. These results are following other previous studies [36, 100-102].

\section{Conclusion}

The present study conclusively supported niosomes as a distinctive drug delivery system with a high degree of entrapment and sustained drug release over a prolonged period of time. Results revealed that the molar ratio of cholesterol and surfactant and presence or absence of charge inducers had a great impact on the general performance of niosomes. Performed invivo studies demonstrated that BMV niosomal gel applied topically has superior sustained antiinflammatory efficacy compared to both the marketed product and BMV plain gel. Thus, BMV-loaded niosomal formulation is a promising carrier system and seems to represent an attractive strategy to enhance the anti-inflammatory efficacy of BMV in treating skin disorders where the local effect is required.

\section{Funding}

This research was funded by the Project's Sector at the National Research Centre, Giza, Egypt (fund number: P11010304).

\section{Acknowledgments}

This research has no acknowledgment.

\section{Conflicts of Interest}

The authors declare no conflict of interest.

\section{References}

1. Becker, D.E. Basic and clinical pharmacology of glucocorticosteroids. Anesth. Prog. 2013, 60, 25-31, https://doi.org/10.2344/0003-3006-60.1.25.

2. Fresta, M.; Puglisi, G. Corticosteroid dermal delivery with skin-lipid liposomes. J. Control. Release 1997, 44, 141-151, https://doi.org/10.1016/S0168-3659(96)01519-2. 
3. Santos Maia, C.; Mehnert, W.; Schaller, M.; Korting, H.C.; Gysler, A.; Haberland, A.; Schäfer-Korting, M. Drug targeting by solid lipid nanoparticles for dermal use. J. Drug Target 2002, 10, 489-495, https://doi.org/10.1080/1061186021000038364.

4. Ag Seleci, D.; Maurer, V.; Stahl, F.; Scheper, T.; Garnweitner, G. Rapid Microfluidic Preparation of Niosomes for Targeted Drug Delivery. Int. J. Mol. Sci. 2019, 20, https://doi.org/10.3390/ijms20194696.

5. Carafa, M.; Santucci, E.; Lucania, G. Lidocaine-loaded non-ionic surfactant vesicles: characterization and in vitro permeation studies. Int. J. Pharm. 2002, 231, 21-32, https://doi.org/10.1016/s0378-5173(01)008286.

6. Mahale, N.B.; Thakkar, P.D.; Mali, R.G.; Walunj, D.R.; Chaudhari, S.R. Niosomes: novel sustained release non-ionic stable vesicular systems--an overview. Adv. Colloid Interface Sci. 2012, 183-184, 46-54, https://doi.org/10.1016/j.cis.2012.08.002.

7. Sharma, A.; Kumar, L.; Kumar, P.; Prasad, N.; Rastogi, V. Niosomes: a promising approach in drug delivery systems. J. Drug Deliv. Ther. 2019, 9, 635-642.

8. Shirsand, S.B.; Keshavshetti, G.G. Recent advances in niosomal drug delivery-A review. Res. J. Life Sci. Bioinform. Pharm. Chem. Sci. 2019, 5, 514-531, https://doi.org/10.26479/2019.0503.43.

9. Shirsand, S.; Para, M.; Nagendrakumar, D.; Kanani, K.; Keerthy, D. Formulation and evaluation of Ketoconazole niosomal gel drug delivery system. Int. J. Pharm. Investig. 2012, 2, 201-207, https://doi.org/10.4103/2230-973x.107002.

10. Rahimpour, Y.; Hamishehkar, H. Niosomes as carrier in dermal drug delivery. In: Recent Advances in Novel Drug Carrier Systems. InTech, 2012; pp. 141-147, https://doi.org/10.5772/51729.

11. Zhang, J.; Smith, E. Percutaneous permeation of betamethasone 17-valerate incorporated in lipid nanoparticles. J. Pharm. Sci. 2011, 100, 896-903, https://doi.org/10.1002/jps.22329.

12. Swartz, S.L.; Dluhy, R.G. Corticosteroids: clinical pharmacology and therapeutic use. Drugs 1978, 16, 238255, https://doi.org/10.2165/00003495-197816030-00006.

13. Carlos, G.; Uribe, P.; Fernández-Peñas, P. Rational use of topical corticosteroids. Aust. Prescr. 2013, 36, 56, https://doi.org/10.18773/austprescr.2013.063.

14. Kong, X.; Zhao, Y.; Quan, P.; Fang, L. Development of a topical ointment of betamethasone dipropionate loaded nanostructured lipid carrier. Asian J. Pharm. Sci. 2016, 11, 248-254, https://doi.org/10.1016/j.ajps.2015.07.005.

15. Hanna, P.A.; Ghorab, M.M.; Gad, S. Development of Betamethasone Dipropionate-Loaded Nanostructured Lipid Carriers for Topical and Transdermal Delivery. Antiinflamm. Antiallergy Agents Med. Chem. 2019, 18, 26-44, https://doi.org/10.2174/1871523017666181115104159.

16. Tung, N.T.; Vu, V.D.; Nguyen, P.L. DoE-based development, physicochemical characterization, and pharmacological evaluation of a topical hydrogel containing betamethasone dipropionate microemulsion. Colloids Surf. B Biointerfaces 2019, 181, 480-488, https://doi.org/10.1016/j.colsurfb.2019.06.002.

17. Wang, W.; Shu, G.F.; Lu, K.J.; Xu, X.L.; Sun, M.C.; Qi, J.; Huang, Q.L.; Tan, W.Q.; Du, Y.Z. Flexible liposomal gel dual-loaded with all-trans retinoic acid and betamethasone for enhanced therapeutic efficiency of psoriasis. J. Nanobiotechnology 2020, 18, 1-14, https://doi.org/10.1186/s12951-020-00635-0.

18. González-Paredes, A.; Manconi, M.; Caddeo, C.; Ramos-Cormenzana, A.; Monteoliva-Sánchez, M.; Fadda, A.M. Archaeosomes as carriers for topical delivery of betamethasone dipropionate: in vitro skin permeation study. J. Liposome Res. 2010, 20, 269-276, https://doi.org/10.3109/08982100903402962.

19. Baillie, A.J.; Florence, A.T.; Hume, L.R.; Muirhead, G.T.; Rogerson, A. The preparation and properties of niosomes--non-ionic surfactant vesicles. J. Pharm. Pharmacol. 1985, 37, 863-868, https://doi.org/10.1111/j.2042-7158.1985.tb04990.x.

20. Usama, A.; Fetih, G.; El-Faham, T. Performance of meloxicam niosomal gel formulations for transdermal drug delivery. Br. J. Pharm. Res. 2016, 12, 1-14, https://doi.org/10.9734/BJPR/2016/26985.

21. Sankar, V.; Ruckmani, K.; Durga, S.; Jailani, S. Proniosomes as drug carriers. Pak. J. Pharm. Sci. 2010, 23, 103-107, https://doi.org/10.13040/IJPSR.0975-8232.3(12).4617-25.

22. Sharma, R.; Dua, J.S.; Prasad, D.; Hira, S. Advancement in Novel Drug Delivery System: Niosomes. J. drug deliv. ther. 2019, 9, 995-1001.

23. Attia Shafie, M.A.; Fayek, H.H.M. Formulation and evaluation of betamethasone sodium phosphate loaded nanoparticles for ophthalmic delivery. J. Clin. Exp. Ophthalmol. 2013, 4, 1-11, https://doi.org/10.4172/21559570.1000273.

24. Durak, S.; Esmaeili Rad, M.; Alp Yetisgin, A.; Eda Sutova, H.; Kutlu, O.; Cetinel, S.; Zarrabi, A. Niosomal Drug Delivery Systems for Ocular Disease-Recent Advances and Future Prospects. Nanomaterials (Basel, Switzerland) 2020, 10, 1-29, https://doi.org/10.3390/nano10061191.

25. Fang, J.-Y.; Yu, S.-Y.; Wu, P.-C.; Huang, Y.-B.; Tsai, Y.-H. In vitro skin permeation of estradiol from various proniosome formulations. Int. J. Pharm. 2001, 215, 91-99, https://doi.org/10.1016/S03785173(00)00669-4.

26. El-Mahdy, M.M.; Hassan, A.S.; El-Badry, M.; El-Gindy, G.E.-D.A. Performance of Curcumin in Nanosized Carriers Niosomes and Ethosomes as Potential Anti-Inflammatory Delivery System for Topical Application. Bulletin of Pharmaceutical Sciences. Assiut 2020, 43, 105-122, https://dx.doi.org/10.21608/bfsa.2020.93599. 
27. Shrivastava, B. Topical Combination Delivery of Benzoyl Peroxide and Adapalene Niosomal Gel for Acne Treatment. Asian J. Pharm. 2019, 13, 1-12, https://doi.org/10.22377/ajp.v13i04.3409.

28. Li, X.; Zhang, Z.; Li, J.; Sun, S.; Weng, Y.; Chen, H. Diclofenac/biodegradable polymer micelles for ocular applications. Nanoscale 2012, 4, 4667-4673, https://doi.org/10.1039/c2nr30924f.

29. Juliano, R.L.; Stamp, D. Pharmacokinetics of liposome-encapsulated anti-tumor drugs. Studies with vinblastine, actinomycin D, cytosine arabinoside, and daunomycin. Biochem. Pharmacol. 1978, 27, 21-27, https://doi.org/10.1016/0006-2952(78)90252-6.

30. Khalil, R.M.; Abd-Elbary, A.; Kassem, M.A.; El Ridy, M.S.; Samra, M.M.A.; Awad, G.E.; Mansy, S.S. Formulation and characterization of nystatin-loaded nanostructured lipid carriers for topical delivery against cutaneous Candidiasis. Br. J. Pharm. Res. 2014, 4, 490-512, https://doi.org/10.9734/bjpr/2014/7055.

31. Hemati, M.; Haghiralsadat, F.; Yazdian, F.; Jafari, F.; Moradi, A.; Malekpour-Dehkordi, Z. Development and characterization of a novel cationic PEGylated niosome-encapsulated forms of doxorubicin, quercetin and siRNA for the treatment of cancer by using combination therapy. Artif. Cells Nanomed. Biotechnol. 2019, 47, 1295-1311, https://doi.org/10.1080/21691401.2018.1489271.

32. Machado, N.D.; Fernández, M.A.; Häring, M.; Saldías, C.; Díaz, D.D. Niosomes encapsulated in biohydrogels for tunable delivery of phytoalexin resveratrol. RSC advances 2019, 9, 7601-7609, https://doi.org/10.1039/c8ra09655d.

33. Korsmeyer, R.W.; Gurny, R.; Doelker, E.; Buri, P.; Peppas, N.A. Mechanisms of solute release from porous hydrophilic polymers. Int. J. Pharm. 1983, 15, 25-35, https://doi.org/10.1016/0378-5173(83)90064-9.

34. Karasulu, H.; Ertan, G.; Köse, T. Modeling of theophylline release from different geometrical erodible tablets. Eur. J. Pharm. Biopharm. 2000, 49, 177-182, https://doi.org/10.1016/s0939-6411(99)00082-x.

35. Jin, Y.; Wen, J.; Garg, S.; Liu, D.; Zhou, Y.; Teng, L.; Zhang, W. Development of a novel niosomal system for oral delivery of Ginkgo biloba extract. Int. J. Nanomedicine 2013, 8, 421-430, https://doi.org/10.2147/ijn.s37984.

36. Fathalla, D.; Abdel-Mageed, A.; Abdel-Hamid, F.; Ahmed, M. In-vitro and in-vivo evaluation of niosomal gel containing aceclofenac for sustained drug delivery. Int. J. Pharm. Sci. Res. 2014, 1, 1-12, https://doi.org/10.15344/2394-1502/2014/105.

37. Chen, M.X.; Alexander, K.S.; Baki, G. Formulation and Evaluation of Antibacterial Creams and Gels Containing Metal Ions for Topical Application. J. Pharm. (Cairo) 2016, 2016, 1-10, https://doi.org/10.1155/2016/5754349.

38. Kassem, A.A.; El-Alim, S.H.A.; Asfour, M.H. Enhancement of 8-methoxypsoralen topical delivery via nanosized niosomal vesicles: Formulation development, in vitro and in vivo evaluation of skin deposition. Int. J. pharm. 2017, 517, 256-268, https://doi.org/10.1016/j.ijpharm.2016.12.018.

39. Abdel-Salam, F.S.; Elkheshen, S.A.; Mahmoud, A.A.; Ammar, H.O. Diflucortolone valerate loaded solid lipid nanoparticles as a semisolid topical delivery system. Bulletin of Faculty of Pharmacy, Cairo University 2016, 54, 1-7, https://doi.org/10.1016/j.bfopcu.2015.11.002.

40. Basha, M.; Abd El-Alim, S.H.; Kassem, A.A.; El Awdan, S.; Awad, G. Benzocaine loaded solid lipid nanoparticles: Formulation design, in vitro and in vivo evaluation of local anesthetic effect. Curr. Drug Deliv. 2015, 12, 680-692, https://doi.org/10.2174/1567201812666150703115126.

41. Patel, K.K.; Kumar, P.; Thakkar, H.P. Formulation of niosomal gel for enhanced transdermal lopinavir delivery and its comparative evaluation with ethosomal gel. AAPS PharmSciTech 2012, 13, 1502-1510, https://doi.org/10.1208/s12249-012-9871-7.

42. Das, M.K.; Bhattacharya, A.; Ghosal, S.K. Effect of different terpene-containing essential oils on percutaneous absorption of trazodone hydrochloride through mouse epidermis. Drug Deliv. 2006, 13, 425431, https://doi.org/10.1080/10717540500395064.

43. El-Ridy, M.; ElRahman, A.A.; Awad, G.; Khalil, R.; Younis, M. In-vitro and in-vivo evaluation of niosomes containing celecoxib. Int. J. Pharm. Sci. Res. 2014, 5, 4677-4688, https://doi.org/10.13040/IJPSR.09758232.5(11).4677-88.

44. Tran, Y.T.H.; Tran, G.N.; Hoang, A.L.; Vu, G.T.T. Niosomes loaded with diclofenac for transdermal administration: Physico-chemical characterization, ex vivo and in vivo skin permeation studies. J. Appl. Pharm. Sci. 2020, 10, 053-061, https://doi.org/10.7324/JAPS.2020.101207.

45. Simon, A.; Amaro, M.I.; Healy, A.M.; Cabral, L.M.; de Sousa, V.P. Comparative evaluation of rivastigmine permeation from a transdermal system in the Franz cell using synthetic membranes and pig ear skin with in vivo-in vitro correlation. Int. J. Pharm. 2016, 512, 234-241, https://doi.org/10.1016/j.ijpharm.2016.08.052.

46. Fang, J.Y.; Hong, C.T.; Chiu, W.T.; Wang, Y.Y. Effect of liposomes and niosomes on skin permeation of enoxacin. Int. J. Pharm. 2001, 219, 61-72, https://doi.org/10.1016/s0378-5173(01)00627-5.

47. Alam, M.; Ali, M.; Alam, N.; Anwer, T.; Imam, F.; Siddiqui, M.R.; Shamim, M. Design and characterization of nanostructure topical gel of betamethasone dipropionate for psoriasis. J. Appl. Pharm. Sci. 2012, 2, 148158.

48. Piplani, P.; Kumar, P.; Rohilla, A.; Singla, S.; Kaur, I.P. Development and evaluation of an ocular niosomal delivery system for some newly synthesized Beta blockers. Asian Journal of Biomedical and Pharmaceutical Sciences 2015, 4, 8-17, https://doi.org/10.15272/ajbps.v4i40.634. 
49. ICH Q2(R1) Validation of Analytical Procedures: Text and Methodology.International Conference on Harmonization, Geneva, Switzerland; ICH 2005. Available from: https://www.gmpcompliance.org/files/guidemgr/Q2(R1).pdf.

50. Pecoraro, B.; Tutone, M.; Hoffman, E.; Hutter, V.; Almerico, A.M.; Traynor, M. Predicting Skin Permeability by Means of Computational Approaches: Reliability and Caveats in Pharmaceutical Studies. $J$. Chem. Inf. Model 2019, 59, 1759-1771, https://doi.org/10.1021/acs.jcim.8b00934.

51. Li, Y.; Wang, C.; Wang, J.; Chu, T.; Zhao, L.; Zhao, L. Permeation-enhancing effects and mechanisms of O-acylterpineol on isosorbide dinitrate: mechanistic insights based on ATR-FTIR spectroscopy, molecular modeling, and CLSM images. Drug Deliv. 2019, 26, 107-119, https://doi.org/10.1080/10717544.2018.1561764.

52. Winter, C.A.; Risley, E.A.; Nuss, G.W. Carrageenin-induced edema in hind paw of the rat as an assay for anti-inflammatory drugs. Proceedings of the Society for Experimental Biology and Medicine 1962, 111, 544547, https://doi.org/10.3181/00379727-111-27849.

53. Mattos Filho, T.R.; Junqueira Mde, S.; Groppo, F.C.; Motta, R.H.; Perazzo, F.F. Effect of betamethasone and diclofenac sodium on serum and tissue concentration of amoxicillin. In vivo study in rats. J. Appl. Oral Sci. 2006, 14, 319-323, https://doi.org/10.1590/s1678-77572006000500004.

54. Levy, L. Carrageenan paw edema in the mouse. Life Sci. 1969, 8, 601-606, https://doi.org/10.1016/00243205(69)90021-6.

55. El Kady, W.M.; Salama, A.A.; Desoukey, S.Y.; Hagag, E.G.; El-Shenawy, S.M.; El-Shanawany, M. Comparative DNA profiling, botanical identification and biological evaluation of Gazania longiscapa DC and Gazania rigens L. Bulletin of Faculty of Pharmacy, Cairo University 2015, 53, 129-145, https://doi.org/10.1016/j.bfopcu.2015.07.001.

56. Chi, S.C.; Jun, H.W. Anti-inflammatory activity of ketoprofen gel on carrageenan-induced paw edema in rats. J. Pharm. Sci. 1990, 79, 974-977, https://doi.org/10.1002/jps.2600791106.

57. Uchegbu, I.F.; Double, J.A.; Turton, J.A.; Florence, A.T. Distribution, metabolism and tumoricidal activity of doxorubicin administered in sorbitan monostearate (Span 60) niosomes in the mouse. Pharm. Res. 1995, 12, 1019-1024, https://doi.org/10.1023/a:1016210515134.

58. Coura, C.O.; Souza, R.B.; Rodrigues, J.A.G.; Vanderlei, E.d.S.O.; de Araújo, I.W.F.; Ribeiro, N.A.; Frota, A.F.; Ribeiro, K.A.; Chaves, H.V.; Pereira, K.M.A. Mechanisms involved in the anti-inflammatory action of a polysulfated fraction from Gracilaria cornea in rats. PLOS One 2015, 10, 1-18, https://doi.org/10.1371/journal.pone.0119319.

59. Hsu, S.-M.; Raine, L. Protein A, avidin, and biotin in immunohistochemistry. J. Histochem. Cytochem. 1981, 29, 1349-1353, https://doi.org/10.1177/29.11.6172466.

60. Vemuri, S.; Rhodes, C.T. Preparation and characterization of liposomes as therapeutic delivery systems: a review. Pharm. Acta Helv. 1995, 70, 95-111, https://doi.org/10.1016/0031-6865(95)00010-7.

61. Bernsdorff, C.; Wolf, A.; Winter, R.; Gratton, E. Effect of hydrostatic pressure on water penetration and rotational dynamics in phospholipid-cholesterol bilayers. Biophys. J. 1997, 72, 1264-1277, https://doi.org/10.1016/s0006-3495(97)78773-3.

62. Jankie, S.; Johnson, J.; Adebayo, A.S.; Pillai, G.K.; Pinto Pereira, L.M. Efficacy of Levofloxacin Loaded Non-ionic Surfactant Vesicles (Niosomes) in a Model of Pseudomonas aeruginosa Infected Sprague Dawley Rats. Adv. Pharmacol. Pharm. Sci. 2020, 2020, 1-7, https://doi.org/10.1155/2020/8815969.

63. Uchegbu, I.F.; Vyas, S.P. Non-ionic surfactant based vesicles (niosomes) in drug delivery. Int. J. Pharm. 1998, 172, 33-70, https://doi.org/10.1016/S0378-5173(98)00169-0.

64. Shilakari Asthana, G.; Sharma, P.K.; Asthana, A. In vitro and in vivo evaluation of niosomal formulation for controlled delivery of clarithromycin. Scientifica 2016, 2016, 1-10, https://doi.org/10.1155/2016/6492953.

65. El-Nabarawi, M.A.; Abd El Rehem, R.T.; Teaima, M.; Abary, M.; El-Mofty, H.M.; Khafagy, M.M.; Lotfy, N.M.; Salah, M. Natamycin niosomes as a promising ocular nanosized delivery system with ketorolac tromethamine for dual effects for treatment of candida rabbit keratitis; in vitro/in vivo and histopathological studies. Drug Dev. Ind. Pharm. 2019, 45, 922-936, https://doi.org/10.1080/03639045.2019.1579827.

66. Essa, E.A. Effect of formulation and processing variables on the particle size of sorbitan monopalmitate niosomes. Asian J. Pharm. 2010, 4, 227-233.

67. Yoshioka, T.; Sternberg, B.; Florence, A.T. Preparation and properties of vesicles (niosomes) of sorbitan monoesters (Span 20, 40, 60 and 80) and a sorbitan triester (Span 85). Int. J. Pharm. 1994, 105, 1-6, https://doi.org/10.1016/0378-5173(94)90228-3.

68. Manosroi, A.; Wongtrakul, P.; Manosroi, J.; Sakai, H.; Sugawara, F.; Yuasa, M.; Abe, M. Characterization of vesicles prepared with various non-ionic surfactants mixed with cholesterol. Colloids Surf. B Biointerfaces 2003, 30, 129-138, https://doi.org/10.1016/s0927-7765(03)00080-8.

69. Junyaprasert, V.B.; Singhsa, P.; Suksiriworapong, J.; Chantasart, D. Physicochemical properties and skin permeation of Span 60/Tween 60 niosomes of ellagic acid. Int. J. Pharm. 2012, 423, 303-311, https://doi.org/10.1016/j.ijpharm.2011.11.032. 
70. Bhavani, D.G.; Lakshmi, V.P. Recent advances of non-ionic surfactantbased nano-vesicles (niosomes and proniosomes): a brief review of these in enhancing transdermal delivery of drug. Futur. J. Pharm. Sci. 2020, 6, 1-18, https://doi.org/10.1186/s43094-020-00117-y.

71. Junyaprasert, V.B.; Teeranachaideekul, V.; Supaperm, T. Effect of charged and non-ionic membrane additives on physicochemical properties and stability of niosomes. AAPS PharmSciTech 2008, 9, https://doi.org/10.1208/s12249-008-9121-1.

72. Aggarwal, D.; Kaur, I.P. Improved pharmacodynamics of timolol maleate from a mucoadhesive niosomal ophthalmic drug delivery system. Int. J. Pharm. 2005, 290, 155-159, https://doi.org/10.1016/j.ijpharm.2004.10.026.

73. Namdeo, A.; Jain, N.K. Niosomal delivery of 5-fluorouracil. J. Microencapsul. 1999, 16, 731-40, https://doi.org/10.1080/026520499288672.

74. Hasan, A.A.; Madkor, H.; Wageh, S. Formulation and evaluation of metformin hydrochloride-loaded niosomes as controlled release drug delivery system. Drug Deliv. 2013, 20, 120-6, https://doi.org/10.3109/10717544.2013.779332.

75. Betageri, G.; Parsons, D. Drug encapsulation and release from multilamellar and unilamellar liposomes. Int. J. Pharm. 1992, 81, 235-241, https://doi.org/10.1016/0378-5173(92)90015-t.

76. Khazaeli, P.; Pardakhty, A.; Shoorabi, H. Caffeine-loaded niosomes: characterization and in vitro release studies. Drug Deliv. 2007, 14, 447-52, https://doi.org/10.1080/10717540701603597.

77. Siegel, R.A.; Rathbone, M.J. Overview of controlled release mechanisms. In: Fundamentals and Applications of Controlled Release Drug Delivery. Springer, 2012, pp. 19-43, https://doi.org/10.1007/9781-4614-0881-9_2.

78. Joshi, M.; Patravale, V. Nanostructured lipid carrier (NLC) based gel of celecoxib. Int. J. Pharm. 2008, 346, 124-132, https://doi.org/10.1016/j.ijpharm.2007.05.060.

79. Lu, B.; Huang, Y.; Chen, Z.; Ye, J.; Xu, H.; Chen, W.; Long, X. Niosomal Nanocarriers for Enhanced Skin Delivery of Quercetin with Functions of Anti-Tyrosinase and Antioxidant. Molecules 2019, 24, https://doi.org/10.3390/molecules24122322.

80. Ruckmani, K.; Sankar, V. Formulation and optimization of zidovudine niosomes. AAPS PharmSciTech 2010, 11, 1119-1127, https://doi.org/10.1208/s12249-010-9480-2.

81. Zinatloo-Ajabshir, Z.; Zinatloo-Ajabshir, S. Preparation and characterization of Curcumin niosomal nanoparticles via a simple and eco-friendly route. J. Nanostruct. 2019, 9, 784-790.

82. Singh, G.; Dwivedi, H.; Saraf, S. K.; Saraf, S.A. Niosomal delivery of isoniazid-development and characterization. Trop J. Pharm. Res. 2011, 10, 203-210, https://doi.org/10.4314/tjpr.v10i2.66564.

83. Pando, D.; Gutiérrez, G.; Coca, J.; Pazos, C. Preparation and characterization of niosomes containing resveratrol. J. Food Eng. 2013, 117, 227-234, https://doi.org/10.1016/j.jfoodeng.2013.02.020.

84. Dantas, M.G.B.; Reis, S.A.G.B.; Damasceno, C.M.D.; Rolim, L.A.; Rolim-Neto, P.J.; Carvalho, F.O.; Quintans-Junior, L.J.; Almeida, J.R.G.d.S. Development and evaluation of stability of a gel formulation containing the monoterpene borneol. The Scientific World Journal 2016, 4, 1-4, https://doi.org/10.1155/2016/7394685.

85. Lee, C.H.; Moturi, V.; Lee, Y. Thixotropic property in pharmaceutical formulations. J. Control. Release 2009, 136, 88-98, https://doi.org/10.1016/j.jconrel.2009.02.013.

86. Santoro, M.; Marchetti, P.; Rossi, F.; Perale, G.; Castiglione, F.; Mele, A.; Masi, M. Smart approach to evaluate drug diffusivity in injectable agar-carbomer hydrogels for drug delivery. J. Phys. Chem. B 2011, 115, 2503-2510, https://doi.org/10.1021/jp1111394.

87. Goyal, G.; Garg, T.; Malik, B.; Chauhan, G.; Rath, G.; Goyal, A.K. Development and characterization of niosomal gel for topical delivery of benzoyl peroxide. Drug deliv. 2015, 22, 1027-1042, https://doi.org/10.3109/10717544.2013.855277.

88. Ghica, M.V.; Hîrjău, M.; Lupuleasa, D.; Dinu-Pîrvu, C.-E. Flow and thixotropic parameters for rheological characterization of hydrogels. Molecules 2016, 21, 786-802, https://doi.org/10.3390/molecules21060786.

89. Garg, B.J.; Garg, N.K.; Beg, S.; Singh, B.; Katare, O.P. Nanosized ethosomes-based hydrogel formulations of methoxsalen for enhanced topical delivery against vitiligo: formulation optimization, in vitro evaluation and preclinical assessment. J. Drug Target 2016, 24, 233-246, https://doi.org/10.3109/1061186x.2015.1070855.

90. Alkhalidi, H.M.; Hosny, K.M. Aloe Vera as Topical Hydrogel; Formulation and Rheological Assessment. Int. J. Res. Pharm. Sci. 2019, 10, 3682-3687, https://doi.org/10.26452/ijrps.v10i4.1754.

91. Carvalho, F.C.; Barbi, M.S.; Sarmento, V.H.; Chiavacci, L.A.; Netto, F.M.; Gremião, M.P. Surfactant systems for nasal zidovudine delivery: structural, rheological and mucoadhesive properties. J. Pharm. Pharmacol. 2010, 62, 430-439, https://doi.org/10.1211/jpp.62.04.0004.

92. Barry, B.W. Novel mechanisms and devices to enable successful transdermal drug delivery. Eur. J. Pharm. Sci. 2001, 14, 101-114, https://doi.org/10.1016/s0928-0987(01)00167-1.

93. Muzzalupo, R.; Mazzotta, E. Do niosomes have a place in the field of drug delivery? Expert Opin. Drug Deliv. 2019, 16, 1145-1147, https://doi.org/10.1080/17425247.2019.1663821. 
94. Tabbakhian, M.; Tavakoli, N.; Jaafari, M.R.; Daneshamouz, S. Enhancement of follicular delivery of finasteride by liposomes and niosomes 1 . In vitro permeation and in vivo deposition studies using hamster flank and ear models. Int. J. Pharm. 2006, 323, 1-10, https://doi.org/10.1016/j.ijpharm.2006.05.041.

95. Alvi, I.A.; Madan, J.; Kaushik, D.; Sardana, S.; Pandey, R.S.; Ali, A. Comparative study of transfersomes, liposomes, and niosomes for topical delivery of 5-fluorouracil to skin cancer cells: preparation, characterization, in-vitro release, and cytotoxicity analysis. Anti-cancer drugs 2011, 22, 774-782, https://doi.org/10.1097/CAD.0b013e328346c7d6.

96. Lapteva, M.; Mondon, K.; Möller, M.; Gurny, R.; Kalia, Y.N. Polymeric micelle nanocarriers for the cutaneous delivery of tacrolimus: a targeted approach for the treatment of psoriasis. Mol. Pharm. 2014, 11, 2989-3001, https://doi.org/10.1021/mp400639e.

97. Shinde, U.A.; Kanojiya, S.S. Serratiopeptidase Niosomal Gel with Potential in Topical Delivery. J. Pharm. (Cairo) 2014, 2014, 1-9, https://doi.org/10.1155/2014/382959.

98. Kaur, K.; Jain, S.; Sapra, B.; Tiwary, A.K. Niosomal gel for site-specific sustained delivery of anti-arthritic drug: in vitro-in vivo evaluation. Curr. Drug Deliv. 2007, 4, 276-282, https://doi.org/10.2174/156720107782151250.

99. Jaafari, M.R.; Bavarsad, N.; Bazzaz, B.S.; Samiei, A.; Soroush, D.; Ghorbani, S.; Heravi, M.M.; Khamesipour, A. Effect of topical liposomes containing paromomycin sulfate in the course of Leishmania major infection in susceptible BALB/c mice. Antimicrob. Agents Chemother. 2009, 53, 2259-2265, https://doi.org/10.1128/aac.01319-08.

100. Kumar, G.P.; Rajeshwarrao, P. Nonionic surfactant vesicular systems for effective drug delivery-an overview. Acta Pharm. Sin. B 2011, 1, 208-219, https://doi.org/10.1016/j.apsb.2011.09.002.

101. Muzzalupo, R. Niosomes and proniosomes for enhanced skin delivery. In: Percutaneous Penetration Enhancers Chemical Methods in Penetration Enhancement. Springer: New York, 2016; pp. 147-160, https://doi.org/10.1007/978-3-662-47862-2.

102. Kamboj, S.; Saini, V.; Bala, S.; Sharma, G. Formulation and characterization of drug loaded niosomal gel for anti-inflammatory activity. Int. J. Med. Health Biomed. Bioeng. Pharm. Eng. 2013, 7, 877-881, https://doi.org/10.5281/zenodo.1089463. 